\title{
Multi-Perspective Analysis of Household Carbon Dioxide Emissions from Direct Energy Consumption by the Methods of Logarithmic Mean Divisia Index and $\sigma$ Convergence in Central China
}

\author{
Yueyue Rong ${ }^{1,2}$, Junsong Jia ${ }^{1, *}$, Min Ju ${ }^{1}$, Chundi Chen ${ }^{3, * \mathbb{D}}$, Yangming Zhou ${ }^{1}$ and Yexi Zhong ${ }^{1}$ \\ 1 Key Laboratory of Poyang Lake Wetland and Watershed Research, Ministry of Education, School of \\ Geography and Environment, Jiangxi Normal University, Nanchang 330022, China; \\ rongyueyue@jxnu.edu.cn (Y.R.); jxsddljm@jxnu.edu.cn (M.J.); zhouym@jxnu.edu.cn (Y.Z.); \\ zhongyexi@jxnu.edu.cn (Y.Z.) \\ 2 Graduate School, Jiangxi Normal University, Nanchang 330022, China \\ 3 College of Architecture and Urban Planning, Tongji University, Shanghai 200092, China \\ * Correspondence: jiaaniu@jxnu.edu.cn (J.J.); chundichen@tongji.edu.cn (C.C.)
}

Citation: Rong, Y.; Jia, J.; Ju, M.; Chen, C.; Zhou, Y.; Zhong, Y. Multi-Perspective Analysis of Household Carbon Dioxide Emissions from Direct Energy Consumption by the Methods of Logarithmic Mean Divisia Index and $\sigma$ Convergence in Central China. Sustainability 2021, 13, 9285. https://doi.org/10.3390/su13169285

Academic Editor: Mohammad Aslam Khan Khalil

Received: 18 June 2021

Accepted: 11 August 2021

Published: 18 August 2021

Publisher's Note: MDPI stays neutral with regard to jurisdictional claims in published maps and institutional affiliations.

Copyright: (C) 2021 by the authors Licensee MDPI, Basel, Switzerland. This article is an open access article distributed under the terms and conditions of the Creative Commons Attribution (CC BY) license (https:/ / creativecommons.org/licenses/by/ $4.0 /)$.

\begin{abstract}
Currently, household carbon dioxide $\left(\mathrm{CO}_{2}\right)$ emissions (HCEs) as one of the leading sources of greenhouse gas (GHG) have drawn notable scholarly concern. Thus, here, taking six provinces in the period of 2000-2017 of Central China as a case, we analyzed the characteristics and the driving factors of HCEs from direct energy consumption and three perspectives: Central China as a whole, urban-rural differences, and inter-provincial comparison. The drivers of direct HCEs were analyzed by the Logarithmic Mean Divisia Index (LMDI). The $\sigma$ convergence was adopted for analyzing the trend of inter-provincial differences on the HCEs. The key findings are as follows. First, all the direct HCEs from three perspectives had an obvious growth trend. The total direct HCEs grew from $9596.20 \times 10^{4}$ tonnes in 2000 to $30,318.35 \times 10^{4}$ tonnes in 2017, with an increase of 2.16 times. Electricity and coal use were the primary sources. The urban and rural increases of direct HCEs were up 2.57 times and 1.77 times, respectively. The urban-rural gap of direct HCEs narrowed first and then widened. The direct HCEs in the six provinces varied significantly, but the gap was narrowing. Second, as a whole the per capita consumption expenditure and energy demand were the main drivers to the increment of HCEs, with cumulative contribution rates of $118.19 \%$ and $59.90 \%$. The energy price effect was mainly responsible for the mitigation of HCEs. Third, the similar drivers' trend can also be seen from the perspective of inter-provincial comparison. However, from the perspective of urban and rural difference, the population urban-rural structure effect played a reverse influence on both urban and rural areas. Thus, raising the energy prices appropriately, upgrading the residents' consumption to a sustainable pattern, controlling the growth of population size reasonably, and optimizing the household energy structure might effectively mitigate the growth of HCEs in Central China.
\end{abstract}

Keywords: multi-perspective; household carbon dioxide $\left(\mathrm{CO}_{2}\right)$ emissions (HCEs); Logarithmic Mean Divisia Index (LMDI); $\sigma$ convergence; driving factors; urban-rural differences; inter-provincial comparison

\section{Introduction}

Alleviating climate change is one of the key objectives to realize sustainable development. Human activity was found to have an important effect on global warming by the Intergovernmental Panel on Climate Change (IPCC) [1]. Therefore, reducing the emissions of man-made greenhouse gas (GHG) is one of the fundamental steps to address global climate change [2]. Moreover, the low-carbon economy has gradually become an important target worldwide $[3,4]$. China has been by far the biggest energy user and carbon 
dioxide $\left(\mathrm{CO}_{2}\right)$ emitter. In 2018, China's $\mathrm{CO}_{2}$ emissions accounted for $27.8 \%$ of total $\mathrm{CO}_{2}$ worldwide $[5,6]$. Therefore, a series of targets and policies were formulated by China to mitigate emissions under huge pressure. Recently, it has aimed to reach $\mathrm{CO}_{2}$ summits around 2030, to strive to reach the peak as early as possible and realize carbon neutrality by 2060. Currently, some policies put in place by China are largely focused on the industrial production sector. For example, a review of studies has shown that the pulp and paper industry is one of the largest energy consumers and GHGs and pollutant emitters among manufacturing industries. Many measures for reducing emissions from this industry were proposed [4,7]. Nevertheless, the energy consumption from the household sector has also developed into one of the key drivers of increasing $\mathrm{CO}_{2}$ emissions as the economic level rises [8-10]. In previous studies, household $\mathrm{CO}_{2}$ emissions (HCEs) were reported to account for more than $80 \%$ of the total in the United States (US) [11], more than $70 \%$ in the United Kingdom (UK) and India [12,13], and more than 50\% in Korea [14]. For China, the HCEs represented approximately $40 \%$ [15] and increased yearly, with an annual growth rate of $8.7 \%$ [16]. With the rapid economic growth and improved living standards, the household energy consumption will remain to grow in China. The household sector will likely become one of the major contributors to future GHG emissions. Therefore, reducing the HCEs has become more and more necessary and urgent for achieving carbon mitigation targets.

The HCEs consist of both direct and indirect components [17]. Direct HCEs are associated with the direct consumption of energy products for household power, cooking, heating, and personal travel in daily life $[18,19]$. Indirect HCEs are induced by the energy use of non-energy products consumed by residents in clothing, food, housing, and transportation for all life-cycle links [20]. Diverse models have been put forward to calculate the HCEs in different countries and regions, to understand the status and drivers of these important sources of $\mathrm{CO}_{2}[11,21-24]$. These methods can be classified into four major types [25,26]: emission coefficient method (ECM), consumer lifestyle approach (CLA), life-cycle assessment (LCA), and input-output analysis (IOA). ECM is widely adopted to measure the direct HCEs [27,28], while CLA [11,29,30], IOA [8,31,32], and LCA [33] are mostly used to calculate the indirect HCEs. In the existing literatures on energy consumption from the household sector of China, scholars have analyzed the HCEs in terms of their urban-rural or regional differences. From the perspective of urban-rural differences, numerous researchers have illustrated that the energy uses of urban households were more diversified compared to rural [34], and the corresponding HCEs were also higher than rural [35,36]. Direct HCEs and indirect HCEs dominated rural and urban regions, respectively [19,37]. In addition, the dominant consumption patterns in urban and rural were also different. Wei et al. found that housing made the greatest contribution to $\mathrm{CO}_{2}$ in urban areas, while food contributed most in rural [29]. Furthermore, Zhou et al. [38], Ding et al. [39], Shi et al. [40], Feng et al. [34], Zhang et al. [41], and Li et al. [42] compared the regional differences of household energy use and $\mathrm{CO}_{2}$ emissions based on the national or specific regional perspective in China. The variations mainly relied on economic level, weather conditions, number of households, and energy intensity of each region. Moreover, Zheng et al. investigated the household carbon footprint of 74 major cities in China and found that colder cities in January tended to produce higher HCEs [43].

The decomposition analysis and the Stochastic Impacts by Regression on Population, Affluence, and Technology (STIRPAT) model were usually used for analyzing the drivers of HCEs. The decomposition methods used are Index Decomposition Analysis (IDA) and Structure Decomposition Analysis (SDA). The SDA model can examine the indirect effects of variables on other sectors through input-output data [44]. Li et al. used the SDA model to analyze the changes of indirect HCEs in China during 2000-2014 [31]. Since the SDA requires input-output data, which are normally published every five years in China, it is unsuitable for further studies. Generally, compared with SDA, Logarithmic Mean Divisia Index (LMDI) as one of the IDA methods is a better option to decompose and compare the effects of various driving forces in energy use and $\mathrm{CO}_{2}$ emissions on time- 
series analysis. Using the LMDI model, Zha et al. [45], Shi et al. [40], and Zhou et al. [38] decomposed Chinese HCEs into carbon emissions coefficient, energy structure, energy intensity, income, population and so on. Yin et al. [46], Yang et al. [27], and Wang et al. [35] used a similar method to explore the influencing factors of HCEs in Beijing, Jiangxi, and Guangdong, respectively. Moreover, more and more scholars have used the STIRPAT model to analyze the impact factors of HCEs in recent years, such as Jin et al. [30], Wang et al. [47], Zhu et al. [48], Miao et al. [49], and Wang et al. [50]. The STIRPAT model is more extensible, and more socioeconomic factors can be incorporated. Therefore, the results from the model analysis are also more comprehensive [47].

In summary, the above empirical studies on HCEs are mainly conducted at the national level and single region or province of China as the case. The research perspectives focus mostly on a single analysis of urban-rural difference or regional comparison (Table 1). Few studies have been undertaken to integrate the HCEs from multiple perspectives for a particular region, particularly in underdeveloped or developing regions in China. Thus, in this paper, we take Central China as a study object. Figure 1 shows the location of six provinces in Central China. Central China is the second echelon of China's economic development, accounting for about $10.7 \%$ of the national land, and carrying approximately $26.51 \%$ of the country's population. Statistically, its GDP reached CNY 17.94 trillion in 2017. It plays a significant role in the geographical division of labor in China. Since the implementation of the "Central China Rising Strategy" in 2004, it has become an essential economic growth pole in China. However, meanwhile it can be easily seen that Central China has the enormous potential of increasing $\mathrm{CO}_{2}$ emissions from household consumption. Therefore, it is crucial to study the HCEs in this region. So, we first demonstrated the characteristics and drivers of the HCEs from direct energy consumption and three perspectives: Central China as a whole, urban-rural differences, and inter-provincial comparison. The trend of inter-provincial differences on the HCEs was also analyzed. Finally, some specific countermeasures of emission reduction are proposed for this region's development based on the empirical results. The remainder of the paper is arranged as follows. The detailed methodology and data are in Section 2. The analysis and discussion of the empirical results are presented in Section 3. Section 4 concludes the results and proposes some reasonable countermeasures.

Table 1. The summary of relevant studies on energy consumption and $\mathrm{CO}_{2}$ emissions in the household sector.

\begin{tabular}{|c|c|c|c|c|c|}
\hline Reviewed Paper & Location and Period & Subject & Scale & $\begin{array}{l}\text { Urban-Rural } \\
\text { Differences }\end{array}$ & $\begin{array}{c}\text { Regional } \\
\text { Differences }\end{array}$ \\
\hline Li et al. [19] & $\begin{array}{c}\text { China } \\
1996-2012\end{array}$ & HCEs & Nationwide & $\sqrt{ }$ & \\
\hline Wei et al. [29] & $\begin{array}{l}\text { China } \\
\text { 1999-2002 }\end{array}$ & $\begin{array}{l}\text { Residents' energy use and } \mathrm{CO}_{2} \\
\text { emissions }\end{array}$ & Nationwide & $\sqrt{ }$ & \\
\hline Zha et al. [45] & $\begin{array}{l}\text { China } \\
\text { 1991-2004 }\end{array}$ & Residential $\mathrm{CO}_{2}$ emissions & Nationwide & $\sqrt{ }$ & \\
\hline Liu et al. [15] & $\begin{array}{c}\text { China } \\
1992-2007\end{array}$ & HCEs & Nationwide & $\sqrt{ }$ & \\
\hline Feng et al. [33] & $\begin{array}{l}\text { China and its four regions } \\
\text { 2002-2007 }\end{array}$ & $\begin{array}{c}\text { Household energy use and } \\
\text { HCEs }\end{array}$ & $\begin{array}{l}\text { Nationwide and } \\
\text { Regional }\end{array}$ & $\sqrt{ }$ & $\sqrt{ }$ \\
\hline Shi et al. [40] & $\begin{array}{l}\text { China and its } 30 \text { provinces } \\
\text { 2000-2015 }\end{array}$ & HCEs & $\begin{array}{l}\text { Nationwide and } \\
\text { Provincial }\end{array}$ & & $\sqrt{ }$ \\
\hline Zhou et al. [38] & $\begin{array}{l}\text { China and its } 30 \text { provinces } \\
\text { 2007-2012 }\end{array}$ & $\begin{array}{l}\text { Household living energy use } \\
\text { and } \mathrm{CO}_{2} \text { emissions }\end{array}$ & $\begin{array}{l}\text { Nationwide and } \\
\text { Provincial }\end{array}$ & & $\sqrt{ }$ \\
\hline Zheng et al. [43] & $\begin{array}{l}74 \text { major cities in China } \\
2006\end{array}$ & HCEs & City & & $\sqrt{ }$ \\
\hline Li et al. [42] & $\begin{array}{c}\text { Northwest China } \\
\text { 2011-2012 }\end{array}$ & HCEs & Regional & & $\sqrt{ }$ \\
\hline Ding et al. [39] & $\begin{array}{l}30 \text { provinces in China } \\
1997-2013\end{array}$ & Household energy consumption & Provincial & $\sqrt{ }$ & $\sqrt{ }$ \\
\hline Wang et al. [35] & $\begin{array}{l}\text { Guangdong } \\
1995-2012\end{array}$ & HCEs & Provincial & $\sqrt{ }$ & \\
\hline Jin et al. [30] & $\begin{array}{c}\text { Beijing } \\
1993-2012\end{array}$ & HCEs & City & $\sqrt{ }$ & \\
\hline This paper & $\begin{array}{c}\text { Central } \\
\text { China 2000-2017 }\end{array}$ & HCEs & $\begin{array}{l}\text { Regional and } \\
\text { provincial }\end{array}$ & $\sqrt{ }$ & $\sqrt{ }$ \\
\hline
\end{tabular}




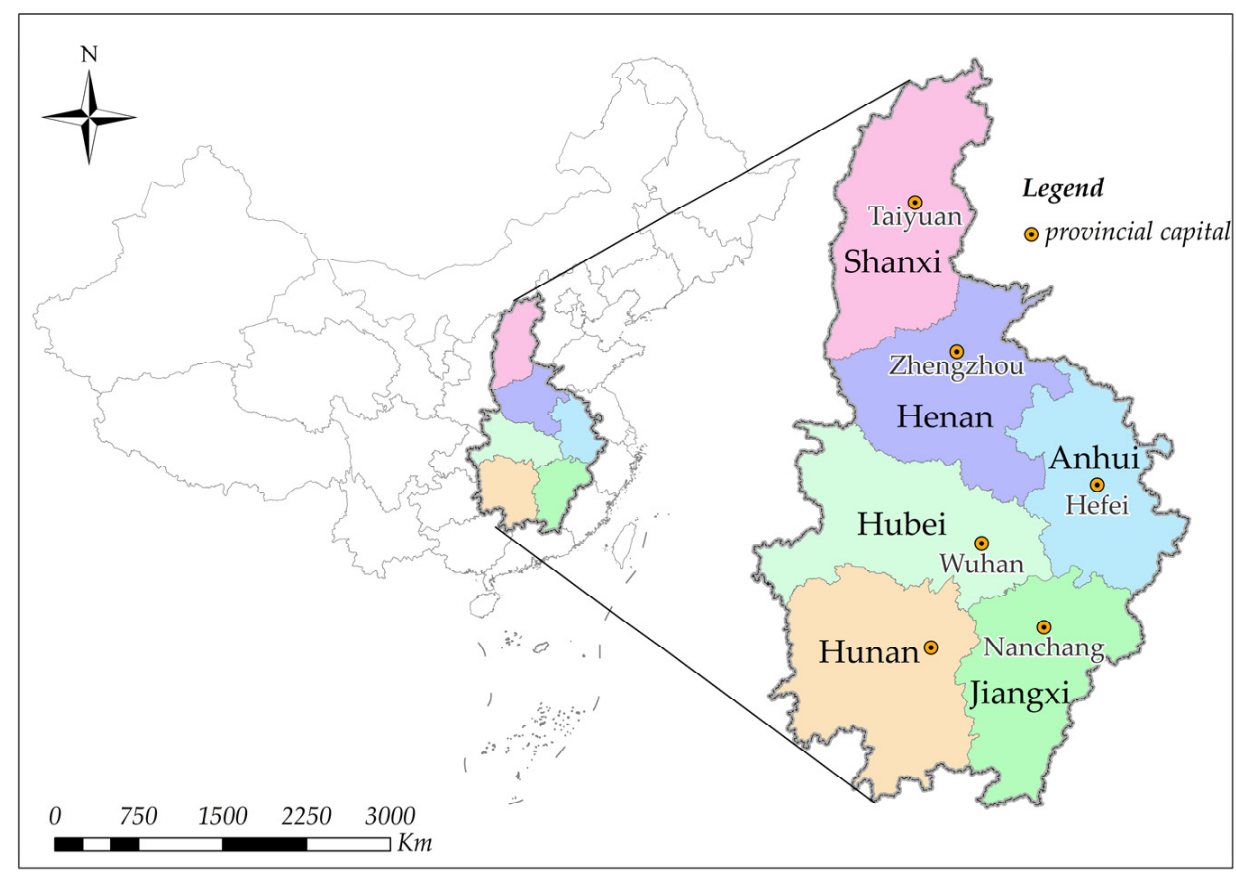

Figure 1. Location of six provinces in Central China.

\section{Materials and Methods}

\subsection{Emission Coefficient Method}

According to the IPCC [28], the direct HCEs were calculated by the consumption amounts of fuel and the corresponding carbon emission coefficients. The equation is:

$$
C=\sum_{i} \sum_{j} C_{i j}=\sum_{i} \sum_{j} E_{i j} \cdot f_{j}
$$

where $C$ is the amount of direct HCEs ( $10^{4}$ tonnes), $i$ is the type of residents, i.e., urban residents and rural residents, $j$ denotes the fuel type, $E_{i j}$ denotes the consumption of energy by resident $i$, and $f_{j}$ the carbon emission coefficient of $j$ fuel type.

\subsection{LMDI Model}

In this paper, we used the LMDI model to explore the driving factors influencing the direct HCEs of Central China. This method can eliminate the residual term in the basic model and handle zero values in data [51,52]. While the basic principle of the LMDI model is the same, the formulas vary with the factors studied. The detailed formula can be expressed as the following extended identity:

$$
\begin{aligned}
C & =\sum_{i} \sum_{j} C_{i j}=\sum_{i} \sum_{j} \frac{C_{i j}}{E_{i j}} \cdot \frac{E_{i j}}{E_{i}} \cdot \frac{E_{i}}{Y_{i e}} \cdot \frac{Y_{i e}}{Y_{i}} \cdot \frac{Y_{i}}{P_{i}} \cdot \frac{P_{i}}{P} \cdot P \\
& =\sum_{i} \sum_{j} F_{i j} \cdot E S_{i j} \cdot E P_{i} \cdot E D_{i} \cdot P C_{i} \cdot P S_{i} \cdot P
\end{aligned}
$$

where the variables are defined in Table 2.

Based on the above formula, we take $C_{0}$ and $C_{t}$ as the direct HCEs in the baseline period and target period. Thus, the change of total direct HCEs $\left(C_{\text {TOT }}\right)$ can be written as:

$$
\Delta C_{T O T}=C_{T}-C_{0}=\Delta C_{F_{i j}}+\Delta C_{E S_{i j}}+\Delta C_{E P_{i}}+\Delta C_{E D_{i}}+\Delta C_{P C_{i}}+\Delta C_{P S_{i}}+\Delta C_{P}
$$


Table 2. Definition of variables.

\begin{tabular}{cl}
\hline Variable & Definition \\
\hline$C$ & Total direct HCEs \\
$C_{i j}$ & Direct HCEs of energy $j$ by resident $i$ \\
$E_{i j}$ & Energy consumption of energy $j$ by resident $i$ \\
$E_{i}$ & Energy consumption of resident $i$ \\
$Y_{i e}$ & Energy consumption expenditure of resident $i$ \\
$Y_{i}$ & Consumption expenditure of resident $i$ \\
$P_{i}$ & Population of resident $i$ \\
$P$ & Total population of Central China \\
$F_{i j}$ & Carbon emission coefficient of energy $j$ by resident $i$ \\
$E S_{i j}$ & Share of energy $j$ in energy consumption by resident $i$ \\
$E P_{i}$ & Energy consumption per unit of residential expenditure for resident $i$ \\
$E D_{i}$ & Share of residential expenditure to consumption expenditure of resident $i$ \\
$P C_{i}$ & Per capita consumption expenditure of resident $i$ \\
$P S_{i}$ & Share of resident $i$ \\
\hline
\end{tabular}

Notably, the $\mathrm{CO}_{2}$ emission coefficients of various fuels are all considered constant when calculating the direct HCEs, which have no contribution to changes in $\mathrm{CO}_{2}$ emissions. Thus, based on the additive LMDI method, we finally analyzed the following six effects: the energy structure effect $\left(\Delta C_{E S}\right)$, energy price effect $\left(\Delta C_{E P}\right)$, energy demand effect $\left(\Delta C_{E D}\right)$, per capita consumption expenditure effect $\left(\Delta C_{P C}\right)$, population urban-rural structure effect $\left(\Delta C_{P S}\right)$, and population size effect $\left(\Delta C_{P}\right)$.

Each sub-effect can be expressed as:

$$
\begin{aligned}
\Delta C_{E S_{i j}} & =\sum_{i} \sum_{j} \frac{C_{i j, T}-C_{i j, 0}}{\ln C_{i j, T}-\ln C_{i j, 0}} \cdot \ln \frac{E S_{i j, T}}{E S_{i j, 0}} \\
\Delta C_{E P_{i}} & =\sum_{i} \sum_{j} \frac{C_{i j, T}-C_{i j, 0}}{\ln C_{i j, T}-\ln C_{i j, 0}} \cdot \ln \frac{E P_{i, T}}{E P_{i, 0}} \\
\Delta C_{E D_{i}} & =\sum_{i} \sum_{j} \frac{C_{i j, T}-C_{i j, 0}}{\ln C_{i j, T}-\ln C_{i j, 0}} \cdot \ln \frac{E D_{i, T}}{E D_{i, 0}} \\
\Delta C_{P C_{i}} & =\sum_{i} \sum_{j} \frac{C_{i j, T}-C_{i j, 0}}{\ln C_{i j, T}-\ln C_{i j, 0}} \cdot \ln \frac{P C_{i, T}}{P C_{i, 0}} \\
\Delta C_{P S_{i}} & =\sum_{i} \sum_{j} \frac{C_{i j, T}-C_{i j, 0}}{\ln C_{i j, T}-\ln C_{i j, 0}} \cdot \ln \frac{P S_{i, T}}{P S_{i, 0}} \\
\Delta C_{P} & =\sum_{i} \sum_{j} \frac{C_{i j, T}-C_{i j, 0}}{\ln C_{i j, T}-\ln C_{i j, 0}} \cdot \ln \frac{P_{T}}{P_{0}}
\end{aligned}
$$

\subsection{Classical Convergence Regression Method- $\sigma$ Convergence}

The trend of inter-provincial differences in direct HCEs across the six provinces can be determined using the classical convergence regression method. The $\sigma$ convergence is mainly tested by the coefficient of variation, which is expressed as:

$$
C V_{t}=\frac{\sqrt{\frac{1}{n-1} \sum_{k=1}^{n}\left(C_{k, t}-\frac{1}{n} \sum_{k=1}^{n} C_{k, t}\right)^{2}}}{\frac{1}{n} \sum_{k=1}^{n} C_{k, t}}
$$

where $C V_{t}$ denotes the coefficient of variation in year $t$ and $C_{k, t}$ denotes the direct HCEs of the $k$ province in year $t$. If $C V_{t}$ keeps decreasing, it means that there is $\sigma$ convergence in 
the direct HCEs in the six provinces, and the difference of direct HCEs in each province is gradually decreasing.

\subsection{Description of the Data}

The data on household energy consumption for urban and rural areas in the six provinces are found in the China Energy Statistical Yearbook (2001-2018) [53]. The energy sources involved in measuring the direct HCEs are raw coal, washed coal, other washed coal, briquettes, coke, coke oven gas, blast furnace gas, converter gas, other gas, gasoline, kerosene, diesel, fuel oil, lubricants, petroleum asphalt, liquefied petroleum gas (LPG), refinery dry gas, other petroleum products, natural gas, liquefied natural gas (LNG), electricity, heat, and other types. It should be noted that heat and electricity are the secondary energy sources with no direct use of fuel, while a large amount of fuel is consumed in the production process. Thus, in this paper, electricity and heat are also considered. The emission coefficients for different types of primary energy can be calculated using the method recommended by the IPCC (2006), as listed in Table A1. Given the complexity of calculating emission factors from electricity and heat, we used the statistical data on average $\mathrm{CO}_{2}$ emissions per unit of electricity supply in the Guidelines for the Preparation of Provincial Greenhouse Gas Inventories (for Trial Implementation) [54]. The emission factors for electricity are shown in Table A2. The emission coefficient of heat adopted $0.11 \mathrm{t}-\mathrm{CO}_{2} / \mathrm{GJ}$ according to the reference of Jia et al. [55]. Relevant data of influencing factors such as consumption expenditure and population size in the six provinces are from Statistical Yearbooks (2001-2018) [56-61]. All the economic data are comparable in that they are converted into 2000 standard prices. The $\mathrm{CO}_{2}$ emission coefficient for standard coal is 2.4567 [54]. The conversion factor of standard coal for various energy types is from the China Energy Statistical Yearbook (Table A1).

\section{Results}

\subsection{Characteristics of the Amount and Structure of Direct HCEs in Central China 3.1.1. Overall Analysis}

Figure 2a shows the trend of direct HCEs in Central China from 2000 to 2017. The direct HCEs kept increasing (except slightly decreasing in 2004 and 2013) by approximately $215.94 \%$ from $9596.20 \times 10^{4}$ tonnes to $30,318.35 \times 10^{4}$ tonnes during 2000-2017, with an annual growth of $7.00 \%$. It accounted for about $28.72 \%, 24.19 \%$, and $24.51 \%$ of national direct HCEs in 2000, 2006, and 2012, respectively (Table 3). The per capita direct HCEs rose from 0.27 tonnes to 0.77 tonnes, with an average annual increase amount and rate of 0.03 tonnes and $6.32 \%$, respectively. All energy types were divided into five categories, and the electricity and coal consumption dominated the direct HCEs. For example, the cumulative share of $\mathrm{CO}_{2}$ emissions from the electricity during 2000-2017, accounted for $46.55 \%$ of total HCEs in Central China (Figure 2b).

Table 3. Comparison of direct HCEs in Central China and the whole of China.

\begin{tabular}{lccc}
\hline \multicolumn{1}{c}{ Carbon Emissions $\left.\mathbf{( 1 0}^{\mathbf{4}} \mathbf{t}\right)$} & $\mathbf{2 0 0 0}$ & $\mathbf{2 0 0 6}$ & $\mathbf{2 0 1 2}$ \\
\hline Total direct HCEs in Central China & $10,485.40$ & $14,248.12$ & $23,701.63$ \\
Total direct HCEs in China & $36,513.00$ & $58,894.00$ & $96,694.00$ \\
Share (\%) & $28.72 \%$ & $24.19 \%$ & $24.51 \%$ \\
Urban direct HCEs in Central China & 4679.08 & 7083.59 & $12,632.23$ \\
Urban direct HCEs in China & $20,931.00$ & $34,841.00$ & $56,614.00$ \\
Share (\%) & $22.35 \%$ & $20.33 \%$ & $22.31 \%$ \\
Rural direct HCEs in Central China & 4917.12 & 7164.53 & $11,069.40$ \\
Rural direct HCEs in China & $15,581.00$ & $24,053.00$ & $40,080.00$ \\
Share (\%) & $31.56 \%$ & $29.79 \%$ & $27.62 \%$ \\
\hline
\end{tabular}




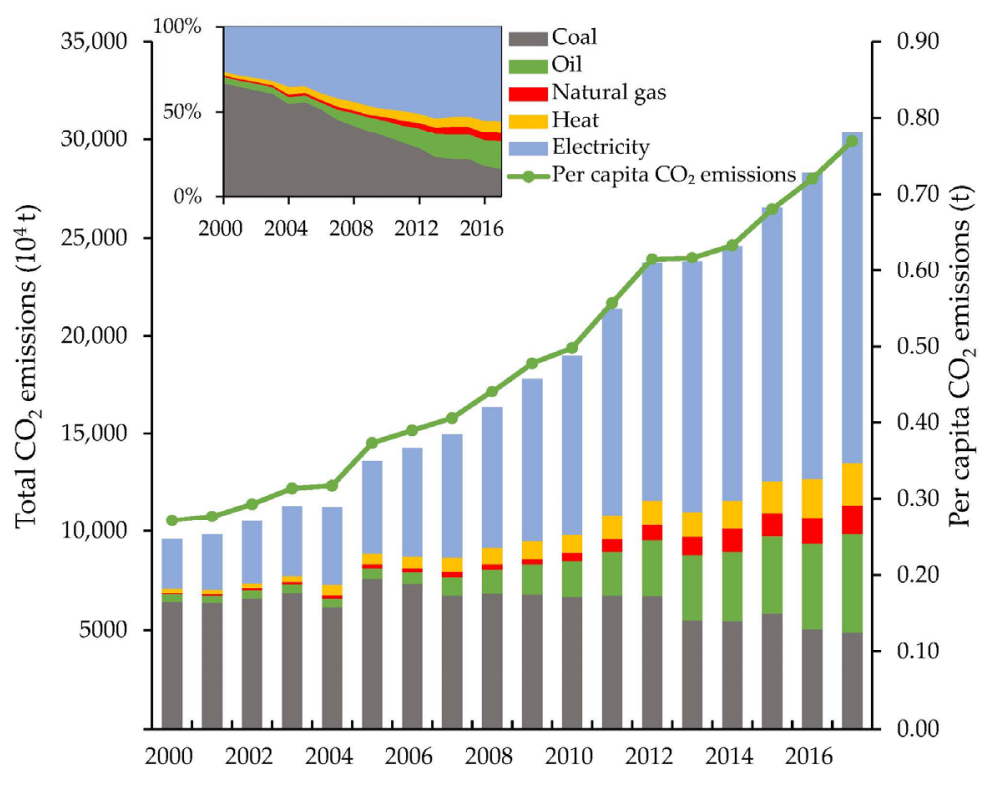

(a)

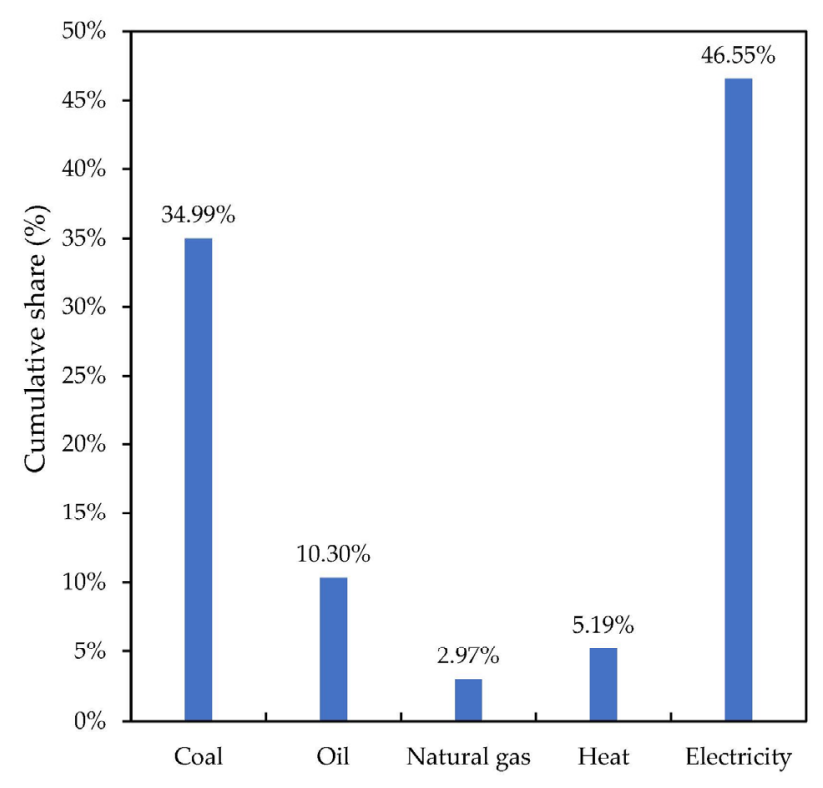

(b)

Figure 2. Trends in the amount and structure of direct HCEs (a) and the cumulative share of $\mathrm{CO}_{2}$ emissions from five energy types during 2000-2017 (b) in Central China.

The structure for direct HCEs has varied significantly in the 2000-2017 years (Figure 2a). The coal-related emissions dropped remarkably from $6423.21 \times 10^{4}$ tonnes to $4875.82 \times 10^{4}$ tonnes, and their share decreased at an average annual rate of $-1.61 \%$ from $66.93 \%$ in 2000 to $16.08 \%$ in 2017 . This trend can be explained by three reasons. Firstly, the utilization rate of coal was improved due to the revolution of coal engineering by technological progress. Secondly, coal-to-gas conversion has been implemented in several locations by China's policy against dry fog. Residential heating has been converted to a centralized type in recent years. Thirdly, the global financial crisis caused a rapid rise in coal prices. On the contrary, the $\mathrm{CO}_{2}$ emissions generated by four other energy use were all up. Significantly, the $\mathrm{CO}_{2}$ emissions of oil grew fastest, followed by electricity. Their average annual growth rates were $16.44 \%$ and $11.82 \%$, respectively. In 2017 , the shares of $\mathrm{CO}_{2}$ emissions from oil and electricity were up to $26.25 \%$ and $55.53 \%$. Meanwhile, the $\mathrm{CO}_{2}$ emissions induced by oil have surpassed those from coal, making it the second-largest energy type. Oil, like diesel, was mainly used for transportation. Since people's demand for transportation has escalated with household income, the number of people purchasing motorcycles and family cars increased. Statistically, the average number of motorcycles and family cars per 100 households owned by residents of Central China was 43.35 and 23.08 in 2017, respectively, which were about 2.75 times and 128.00 times that of 2000 (Table 4). In addition, the growth in household appliances (especially those that consume large amounts of electricity, such as air conditioners) has increased the $\mathrm{CO}_{2}$ emissions from electricity. The average number of air conditioners per 100 households owned by residents of Central China increased by $616.48 \%$ from 13.29 units in 2000 to 95.22 units in 2017. The share of $\mathrm{CO}_{2}$ emissions caused by natural gas has increased over the past few years, while its overall proportion was relatively low at just $4.85 \%$ in 2017. People would prefer cleaner and more convenient natural gas in their energy choices with economic growth and improved living standards. However, the economy of the study region is slightly lower than that of Eastern China, resulting in relatively low use of natural gas. The $\mathrm{CO}_{2}$ emissions of heat also presented an increased tendency $\left(212.64 \times 10^{4}\right.$ tonnes in 2000 and $2157.89 \times 10^{4}$ tonnes in 2017), the share of which increased from $2.22 \%$ in 2000 to $7.12 \%$ in 2017 . In general, the energy use structure has been progressively improved and decarbonized, and the share of clean energy and low-carbon energy use has risen. However, given that heat and electricity 
are produced with coal as the raw material, the energy structure has not been completely altered.

Table 4. Ownership of major durable consumer goods per 100 households at year end in Central China.

\begin{tabular}{cccccc}
\hline Item & $\mathbf{2 0 0 0}$ & $\mathbf{2 0 0 5}$ & $\mathbf{2 0 1 0}$ & $\mathbf{2 0 1 5}$ & $\mathbf{2 0 1 7}$ \\
\hline Family car & 0.18 & 1.37 & 3.48 & 16.48 & 23.08 \\
Motorcycle & 15.74 & 29.97 & 39.12 & 46.25 & 43.35 \\
Washing machine & 54.98 & 55.95 & 75.70 & 83.53 & 89.25 \\
Refrigerator & 43.44 & 46.80 & 70.46 & 88.32 & 94.32 \\
Color TV set & 73.73 & 104.90 & 118.66 & 118.57 & 121.07 \\
Air conditioner & 13.29 & 37.74 & 58.20 & 79.23 & 95.22 \\
Shower heater & 42.68 & 31.64 & 38.95 & 67.33 & 75.78 \\
Mobile telephone & 14.19 & 62.35 & 151.61 & 222.80 & 238.32 \\
Computer & 7.05 & 16.94 & 32.26 & 49.53 & 51.23 \\
\hline
\end{tabular}

\subsubsection{Urban-Rural Differences}

It can be seen that the direct HCEs of both urban and rural households have risen continuously (Figure 3). More $\mathrm{CO}_{2}$ emissions were caused by urban household in most years. The urban and rural direct HCEs significantly increased by 2.57 times (from $4679.08 \times 10^{4}$ tonnes to $16,698.56 \times 10^{4}$ tonnes) and 1.77 times (from $4917.12 \times 10^{4}$ tonnes to $13,619.79 \times 10^{4}$ tonnes), respectively. The corresponding annual average growth rates were $7.77 \%$ and $6.18 \%$. They accounted for approximately $20 \%$ and $30 \%$ of national urban and rural direct HCEs, respectively (Table 3). For the entire study period, the growth amount and rate in urban areas were apparently higher than that of rural. This can be divided into two stages. From 2000 to 2006, rural direct HCEs were higher than those in urban areas. The average annual growth rate of direct HCEs in rural areas was $6.48 \%$, which was lower than that of $7.16 \%$ in urban. The urban-rural ratio of direct HCEs increased to 0.99 from 0.95 , gradually approaching 1 . Thus, the gap between direct HCEs for urban and rural regions was gradually narrowing. After 2006, the direct HCEs in urban areas began to be higher than those of rural areas, and the urban-rural ratio rose from 0.99 to 1.23 , with the gap gradually widening again. The result was consistent with previous studies, such as Zhang at al. [62]. This could be caused by the rapid urbanization. The commercial energy use has increased due to urban population growth, while rural areas are still dominated by non-commercial energy after 2006 [29].

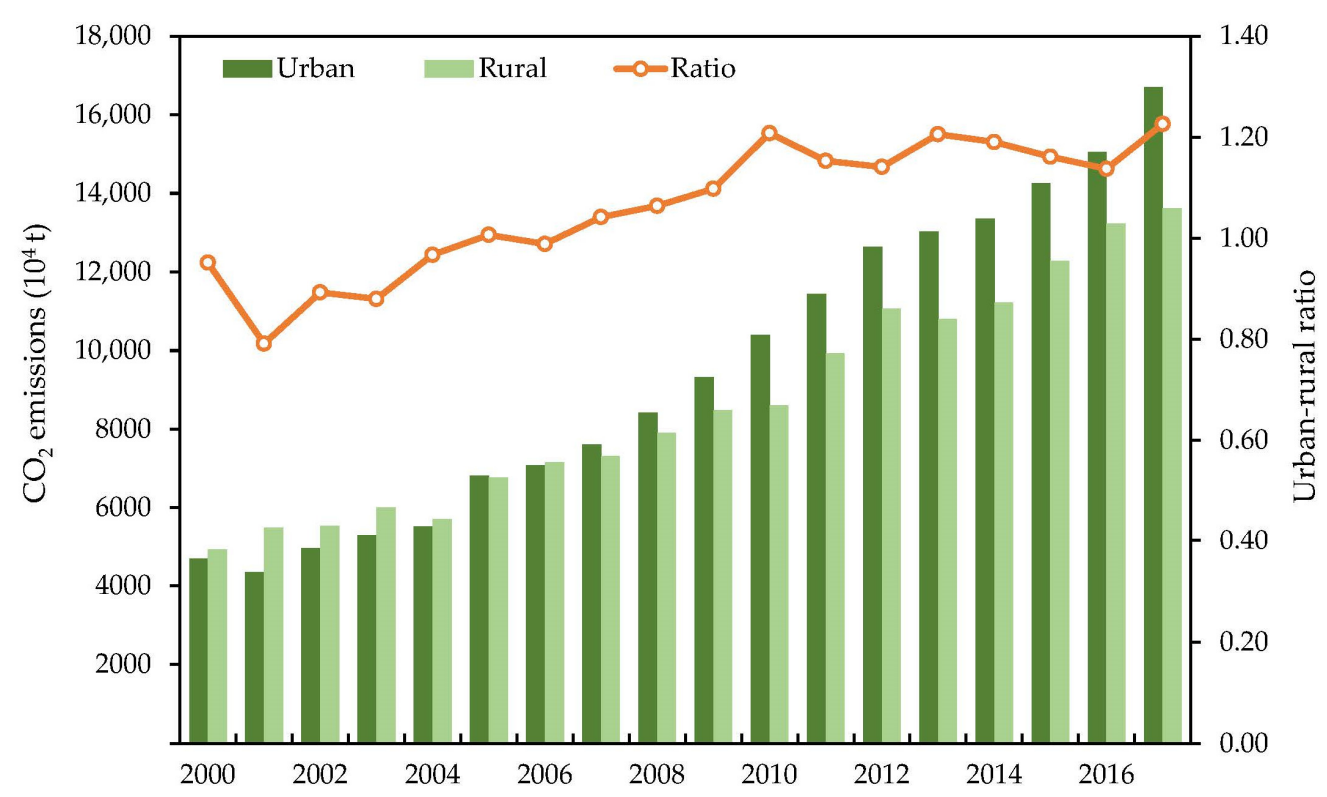

Figure 3. Trends in direct HCEs from urban and rural areas and the urban-rural ratio in Central China. 
There were also many significant differences in the structure of direct HCEs between urban and rural regions. The rural direct HCEs caused by coal consumption were considerably higher than those of urban (Figure $4 \mathrm{~b}$ ), whereas the other four types of energy use were opposite (Figure 4a). A typical dichotomy existed between urban and rural areas in China [29]. The urban-rural differences in the direct HCEs structure were likely caused by substantial variability in income level, energy supply, and energy use habits of urban and rural residents. At present, centralized heating and gas supply have not been taken yet in most rural areas of Central China. The residents mainly use coal for heating and cooking, resulting in heavy coal use. The economic conditions, quality of life, and the ownership of vehicles and household appliances (washing machines, refrigerators, and air conditioners) in urban areas were higher than in rural areas (Table 5), which resulted in greater consumption of oil and electricity in urban areas than in rural. As shown in Table 5, the average number of family cars owned by urban households (per 100 households) was as high as 31.50, while the number was only 14.40 in rural areas in 2017. Natural gas was mainly used for heating and cooking, and indoor heating was centralized for urban dwellers. Urban energy was supplied centrally, which had a specific intensive and scale effect compared to rural areas.

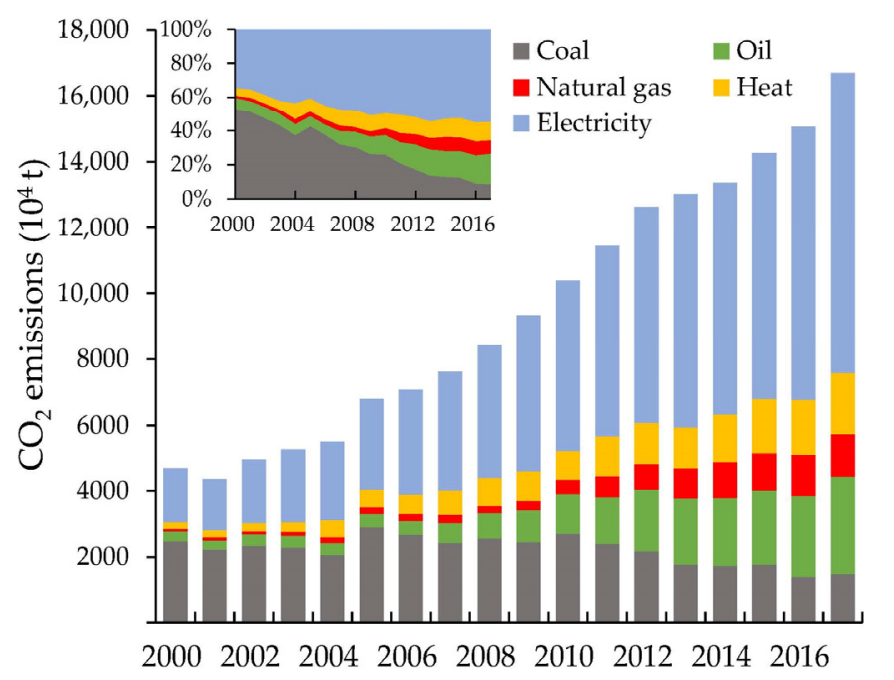

(a) Urban

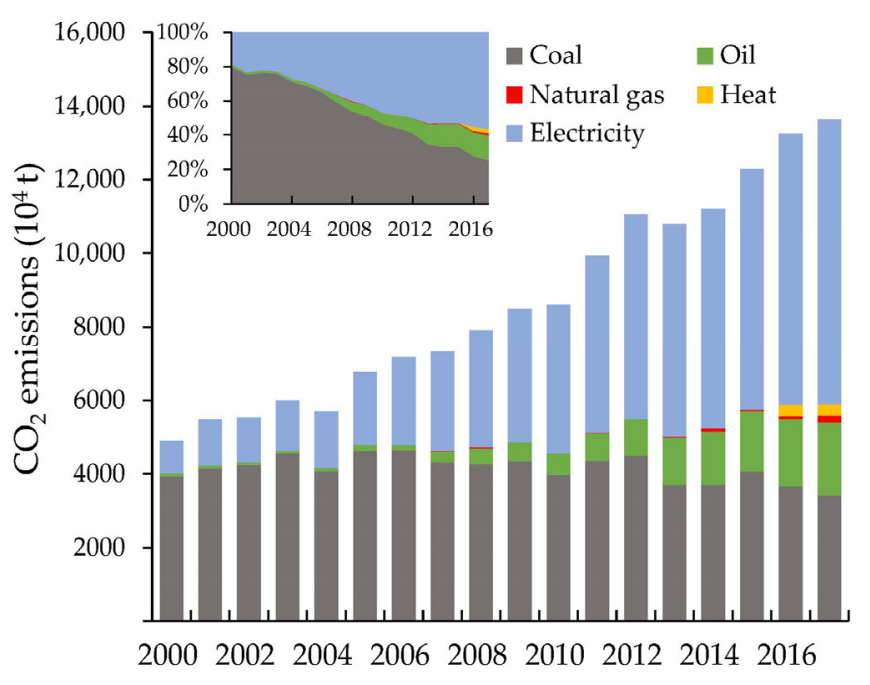

(b) Rural

Figure 4. Trends in the structure of direct HCEs in urban (a) and rural (b) areas in Central China.

Table 5. Urban and rural ownership of major durable consumer goods per 100 households at year end in Central China.

\begin{tabular}{ccccccc}
\hline \multirow{2}{*}{ Item (Unit) } & \multicolumn{2}{c}{ 2000 } & \multicolumn{2}{c}{$\mathbf{2 0 1 0}$} & \multicolumn{2}{c}{$\mathbf{2 0 1 7}$} \\
\cline { 2 - 7 } & Urban & Rural & Urban & Rural & Urban & Rural \\
\hline Family car & 0.35 & - & 6.96 & - & 31.50 & 14.40 \\
Motorcycle & 16.13 & 15.36 & 22.00 & 56.24 & 24.47 & 62.98 \\
Washing machine & 88.83 & 21.14 & 96.95 & 54.45 & 98.53 & 79.40 \\
Refrigerator & 79.76 & 7.13 & 94.80 & 46.13 & 99.43 & 89.05 \\
Color TV set & 108.56 & 38.90 & 130.74 & 106.59 & 122.80 & 119.40 \\
Air conditioner & 26.37 & 0.22 & 100.93 & 15.46 & 135.25 & 54.62 \\
Shower heater & 42.68 & - & 77.90 & - & 91.88 & 59.28 \\
Mobile telephone & 14.19 & - & 167.82 & 135.40 & 236.35 & 240.17 \\
Computer & 7.05 & - & 57.66 & 6.86 & 75.48 & 26.32 \\
\hline
\end{tabular}




\subsubsection{Inter-Provincial Comparison}

In terms of inter-provincial comparison, there was an evident disparity in direct HCEs among the six provinces. Henan Province is the most populous province contributing the largest HCEs during 2000-2017. It contributed a $24.71 \%$ to the total HCEs of Central China, followed by Shanxi (18.52\%), Hubei (17.12\%), Hunan (15.98\%), Anhui (15.11\%), and Jiangxi (8.56\%). Remarkably, the direct HCEs from the six provinces all displayed a fluctuating upward trend during 2000-2017 (Figure 5a). The lowest level of direct HCEs was in Jiangxi, while the overall tendency was on the rise, with an increase of $288.61 \%$ and an average annual growth rate of $8.31 \%$. On the contrary, the direct HCEs of Henan Province were always the highest during the same period, whereas the growth amount and rate were both lower than that of Jiangxi, with an increase of about $175.42 \%$ and an average annual growth rate of $6.14 \%$.

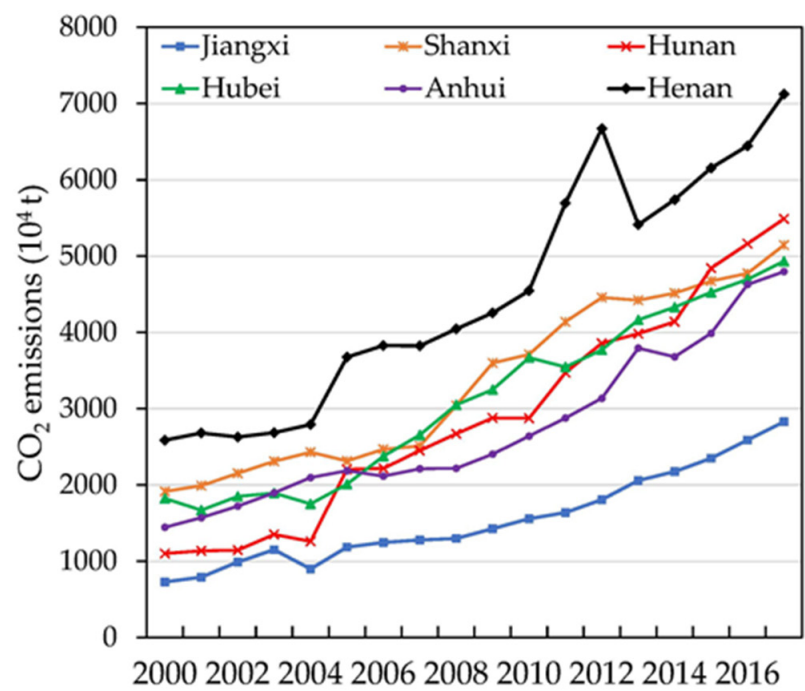

(a)

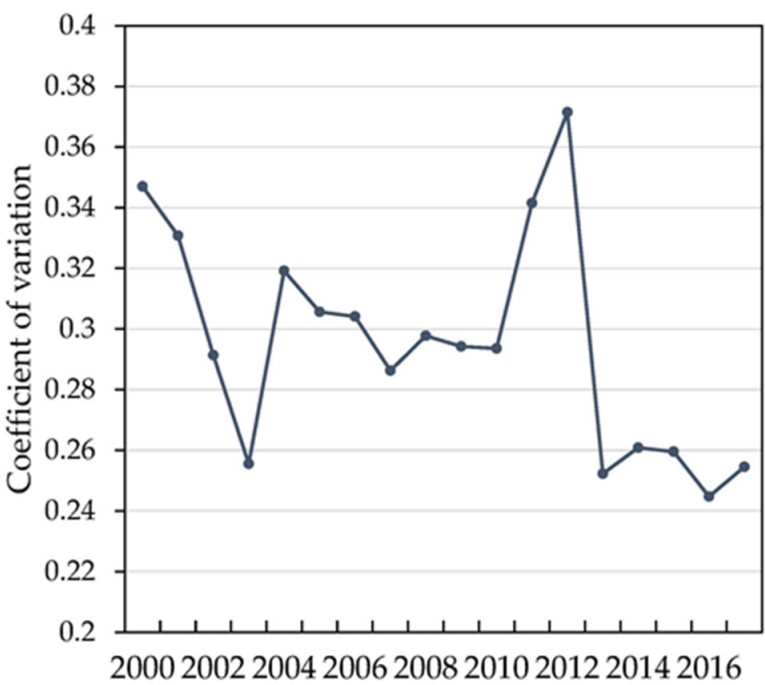

(b)

Figure 5. Trend of the direct HCEs (a) and the coefficient of variation of direct HCEs in six provinces (b).

The HCEs of the remaining four provinces (Hunan, Anhui, Shanxi, and Hubei) were at a medium level during 2000-2017, which can be roughly analyzed in two stages (2000-2005 and 2005-2017). From 2000 to 2005, Hunan Province had the lowest direct HCEs, while it had a speedy growth trend with a growth rate much higher than the other three provinces. The average annual growth rate was $14.9 \%$ and the total increase amount was about $100.3 \%$. The average annual growth rate of Anhui (Shanxi) was $8.64 \%(3.87 \%)$, with the total increase amounts of about $51.32 \%(20.9 \%)$. Hubei's HCEs had the lowest average annual growth rate of only 1.98\%. During 2005-2017, Hunan Province had the highest growth rate of direct HCEs among the four provinces, with an average annual growth rate of $7.9 \%$. Beginning in 2015, the direct HCEs of Hunan reached the highest level among the four provinces gradually and significantly, reaching $5489.00 \times 10^{4}$ tonnes in 2017. Over this period, there was no significant disparity in the growth rate of direct HCEs for the four provinces. The average annual growth rates of other three provinces (Shanxi, Hubei, and Anhui) were 6.88\%, 7.77\%, and 6.77\%, respectively. Their direct HCEs in 2017 were $5145.26 \times 10^{4}$ tonnes, $4932.79 \times 10^{4}$ tonnes, and $4797.57 \times 10^{4}$ tonnes.

To understand whether the difference of direct HCEs among the six provinces is narrowing or widening, we adopted the $\sigma$ convergence test in neoclassical theory to describe it. The coefficient of variation of direct HCEs was used to test. If the coefficient of variation shows a downward trend, there is convergence, indicating that the difference of direct HCEs in the six provinces is progressively decreasing. Based on Equation (10), the coefficient of variation of direct HCEs in the six provinces was calculated. The result 
indicated that the coefficient of variation exhibited an interval increase and decrease from 2000-2017 (Figure 5b). From 2000 to 2003, the coefficient of variation of direct HCEs presented a linearly decreasing trend. The $\sigma$ convergence was obvious over this period. The difference in direct HCEs was steadily declining among the provinces. From 2003 to 2012 , the trend in the coefficient of variation was fluctuating upwards, indicating that there was no $\sigma$ convergence in this period. From 2012 to 2017, it declined first and rebounded somewhat in 2017, which is a dispersion stage. The disparity in direct HCEs increased among the provinces. Overall, the coefficient of variation of direct HCEs decreased from 0.35 in 2000 to 0.25 in 2017, indicating that there was $\sigma$ convergence of direct HCEs in the six provinces. It can also be easily seen that the direct HCEs gap was decreasing in the six provinces from an overall perspective.

The cumulative shares of $\mathrm{CO}_{2}$ emissions from five energy types in each province were calculated (Figure 6). Then, the emission structure of each province was compared and analyzed. First, Shanxi Province took the largest share of $\mathrm{CO}_{2}$ from coal use at $45.14 \%$ in comparison with other provinces, followed by Henan (36.92\%), Hubei (34.59\%), Hunan $(31.92 \%)$, and Anhui (27.71\%). The share of $\mathrm{CO}_{2}$ emissions from coal use in Jiangxi was the lowest, at $26.86 \%$. The coal resources of Shanxi Province were the richest compared to the other five provinces, with more production and usage, so the share of coal consumption and $\mathrm{CO}_{2}$ emissions was the highest. The largest share of $\mathrm{CO}_{2}$ emissions induced by oil was in Hubei, and the smallest share was in Shanxi, with $16.17 \%$ and $3.24 \%$, respectively. The share of $\mathrm{CO}_{2}$ emissions caused by natural gas was relatively small in all six provinces, ranging from $1.72 \%$ to $4.21 \%$. The share of Anhui was the highest and Hunan Province was the lowest. The $\mathrm{CO}_{2}$ emissions generated by electricity consumption represented a large proportion, with Jiangxi, Hunan, and Anhui all exceeding 50\%, while Shanxi represented the least, at only $34.38 \%$. The share of $\mathrm{CO}_{2}$ emissions from heat use in Shanxi was high, at $14.49 \%$. Thus, it can be seen that Shanxi Province had a poor low-carbon energy structure.

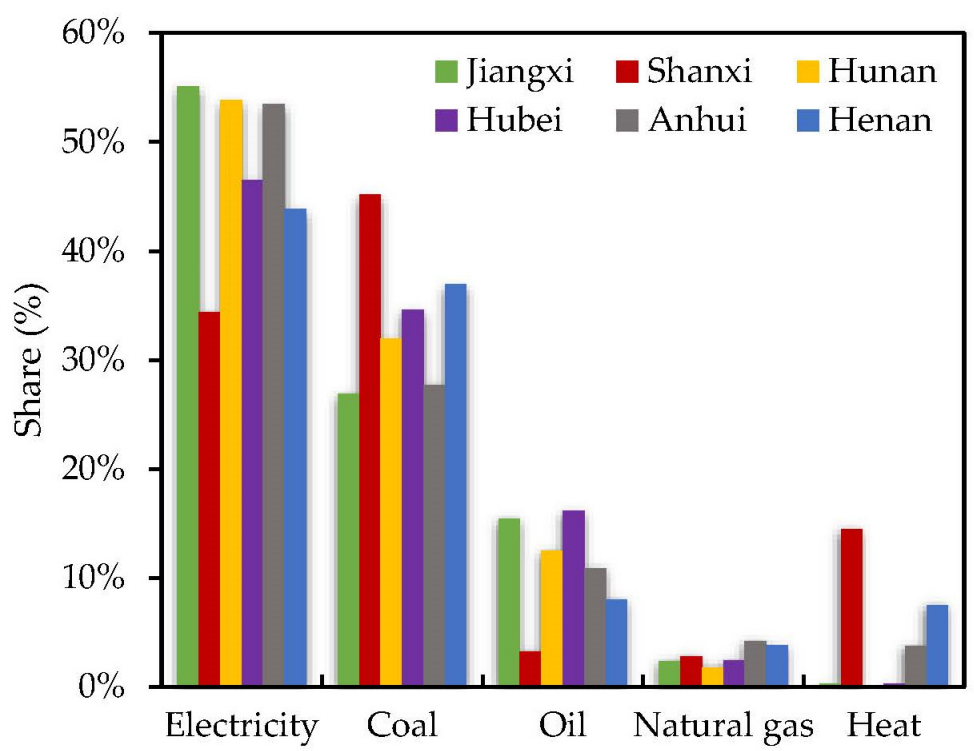

Figure 6. The share of $\mathrm{CO}_{2}$ emissions from five types of energy consumption by provinces in Central China.

\subsection{Decomposition Analysis of Direct HCEs in Central China}

\subsubsection{Overall Analysis}

The complete decomposition results are presented in Figure 7 and Table 3. The cumulative contribution of each driver was calculated from 2000 to 2017 for the ease of analysis (Figure 8a). During the whole study, the change of total direct HCEs was $20,722.15 \times 10^{4}$ tonnes. Generally, the energy structure effect, energy demand effect, per capita consumption expenditure effect, population urban-rural structure effect, and popu- 
lation size effect positively affected the growth of direct HCEs. On the contrary, the energy price effect showed a negative impact, which decreased the direct HCEs. Next, the contribution of each driving factor at four different stages (2000-2005, 2005-2010, 2010-2015, and 2015-2017) is drawn out in Figure 8b.

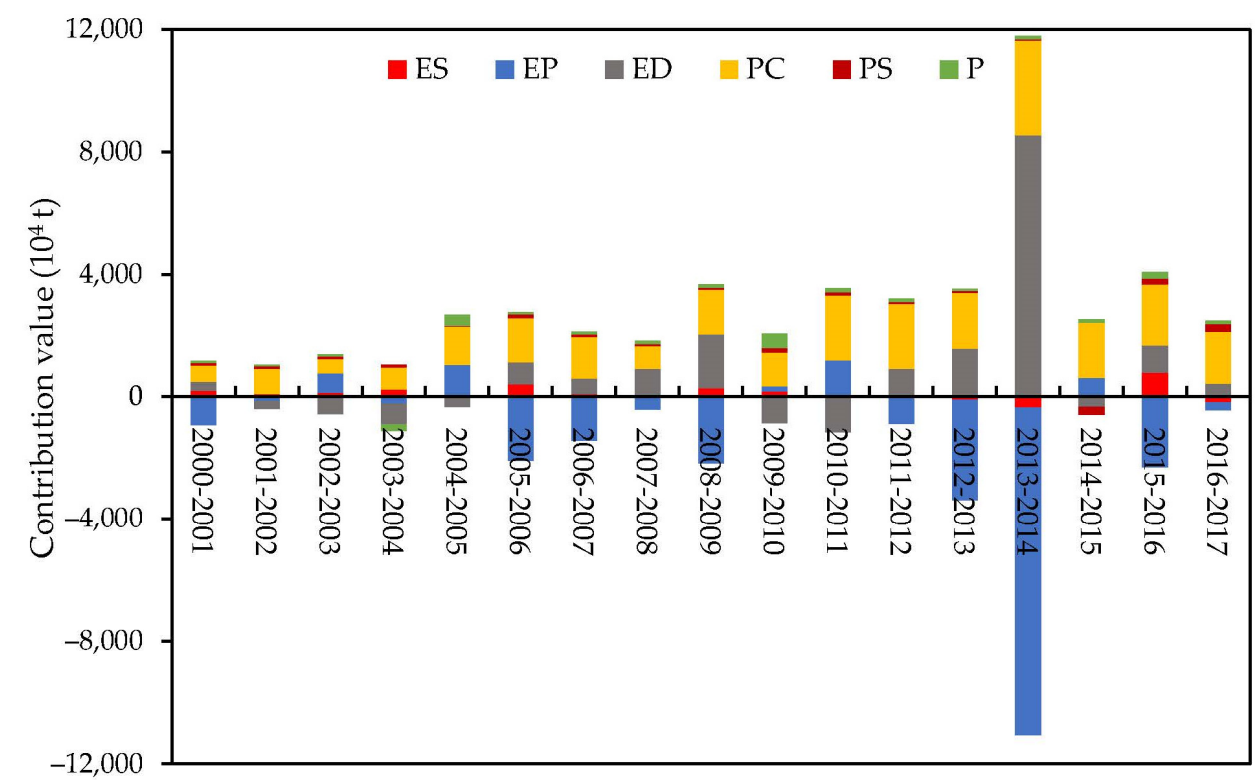

Figure 7. Changes in the contribution values of the driving factors of direct HCEs in Central China from 2000 to 2017.

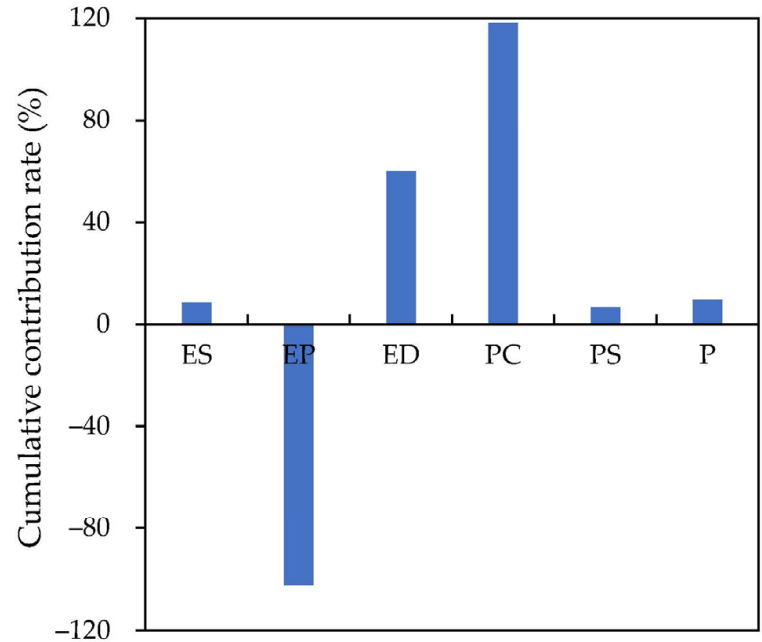

(a)

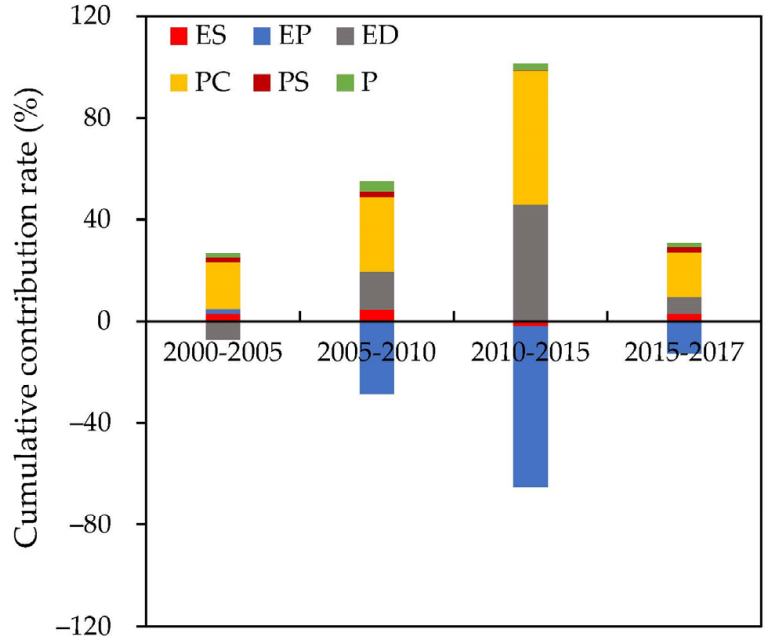

(b)

Figure 8. The cumulative contribution rate of each decomposition factor of direct HCEs in Central China during the period 2000-2017 (a) and at four stages (2000-2005, 2005-2010, 2010-2015, and 2015-2017) (b).

Energy Price Effect

The energy price effect was mainly responsible for mitigating direct HCEs in Central China (Figures 7 and 8a), which was consistent with the previous studies of Yang et al. and Wang et al. [27,35]. However, it was also contrary to the results of a few studies, such as Zhao et al. [63]. The change of energy price decreased 21,228.36 $\times 10^{4}$ tonnes $\mathrm{CO}_{2}$ from 2000 to 2017, with a contribution rate of $-102.44 \%$. Specifically, for each of the four stages, the contribution values (rates) were $382.90 \times 10^{4}$ tonnes $(1.85 \%),-5958.82 \times 10^{4}$ tonnes $(-28.76 \%),-13,064.61 \times 10^{4}$ tonnes $(-63.05 \%)$, and $-2587.84 \times 10^{4}$ tonnes $(-12.49 \%)$, 
respectively (Table 3 and Figure 8b). The corresponding average annual contribution rates in the four stages were $0.37 \%,-5.75 \%,-12.61 \%$, and $-6.24 \%$, respectively (Table 6 ). This mitigation effect may be caused by the increase in the average energy prices during the study period. The Chinese government has launched price deregulation in the energy sector, which has led to an overall increase in energy prices. From 2000 to 2017, the average energy prices in Central China increased to $1.02 \times 10^{4} \mathrm{CNY} /$ tonne of standard coal equivalent (tce) from $0.48 \times 10^{4} \mathrm{CNY} / \mathrm{tce}$, with an average annual growth rate of $4.55 \%$ (Figure $9 \mathrm{a}$ ). The average annual growth rates of energy prices in the four phases were $4.07 \%, 0.82 \%, 5.65 \%$, and $2.26 \%$, respectively. Obviously, the energy price effect had the strongest impact on the decrease of direct HCEs in 2010-2015.

Table 6. The average annual contribution rate of various effects at different stages in Central China.

\begin{tabular}{ccccc}
\hline \multirow{2}{*}{ Effects } & \multicolumn{3}{c}{ Average Annual Contribution Rate (\%) } \\
\cline { 2 - 5 } & $\mathbf{2 0 0 0 - 2 0 0 5}$ & $\mathbf{2 0 0 5 - 2 0 1 0}$ & $\mathbf{2 0 1 0 - 2 0 1 5}$ & $\mathbf{2 0 1 5 - 2 0 1 7}$ \\
\hline Energy structure & 0.58 & 0.90 & -0.39 & 1.48 \\
Energy price & 0.37 & -5.75 & -12.61 & -6.24 \\
Energy demand & -1.42 & 2.95 & 9.18 & 3.19 \\
Per capita consumption expenditure & 3.63 & 5.92 & 10.55 & 8.87 \\
Population urban-rural structure & 0.37 & 0.46 & 0.04 & 1.09 \\
Population size & 0.31 & 0.76 & 0.51 & 0.74 \\
\hline
\end{tabular}

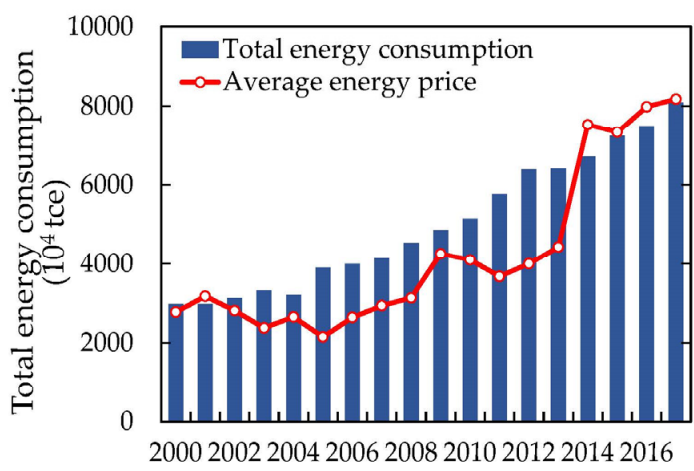

(a)

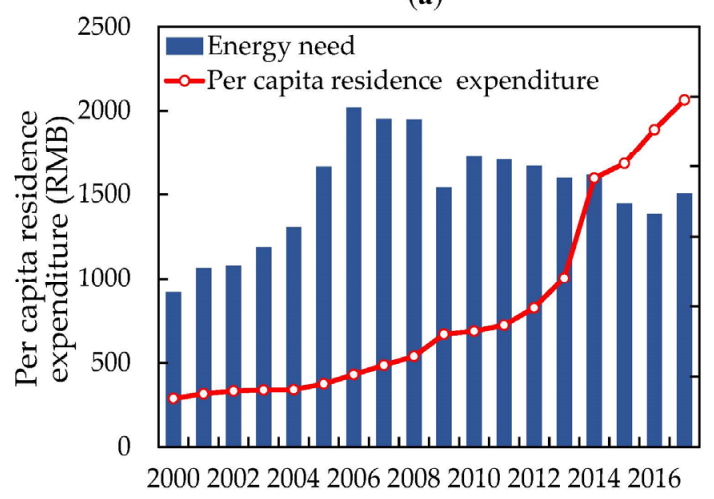

(c)

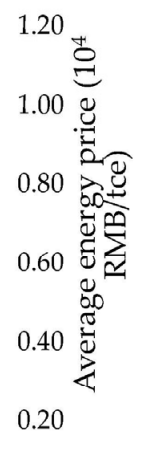

$14.5 \%$

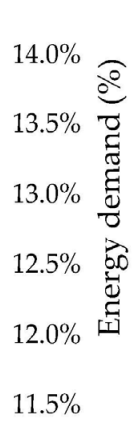

$11.5 \%$

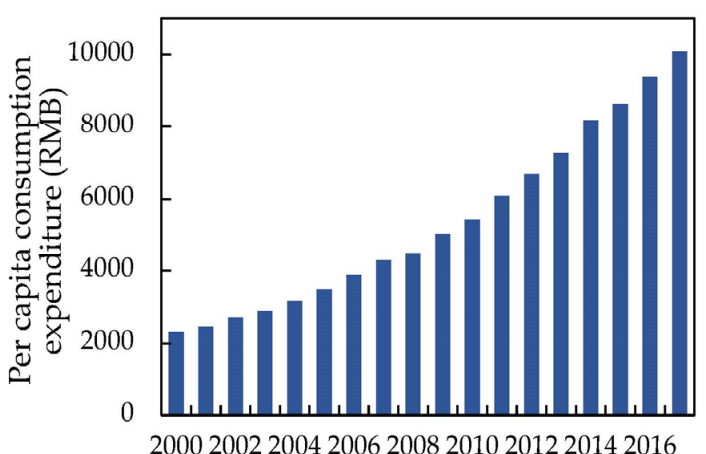

(b)

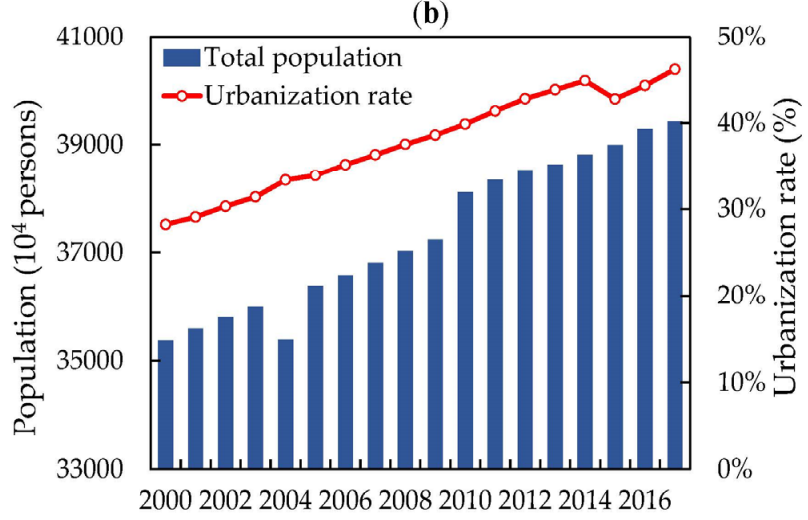

(d)

Figure 9. Variation trend of various influencing factors of direct HCEs in Central China. (a) Energy price; (b) Per capita consumption expenditure; (c) Per capita residence expenditure and energy demand; (d) Population size and urbanization rate.

Per Capita Consumption Expenditure Effect and Energy Demand Effect

The per capita consumption expenditure may, to some extent, reflect the living standard of a region. It represents the residential energy consumption level with the energy demand together. The per capita consumption expenditure effect played the most important role in promoting the growth of direct HCEs (Figures 7 and 8a). It contributed a total 
of $24,490.81 \times 10^{4}$ tonnes $\mathrm{CO}_{2}$ over the study period and accounted for $118.19 \%$ of total change of direct HCEs. Meanwhile, the energy demand was another major contributor for the increment of direct HCEs. It contributed 12,413.03 $\times 10^{4}$ tonnes $\mathrm{CO}_{2}$ and the contribution rate was $59.90 \%$. Concretely, in the four stages, the corresponding contribution values (rates) were $3757.91 \times 10^{4}$ tonnes $(18.13 \%), 6130.93 \times 10^{4}$ tonnes $(29.59 \%)$, $10,926.11 \times 10^{4}$ tonnes $(52.73 \%)$, and $3675.86 \times 10^{4}$ tonnes $(17.74 \%)$ for the per capita consumption expenditure effect, and $-1472.68 \times 10^{4}$ tonnes $(-7.11 \%), 3051.96 \times 10^{4}$ tonnes $(14.73 \%), 9511.01 \times 10^{4}$ tonnes $(45.90 \%)$, and $1322.74 \times 10^{4}$ tonnes $(6.38 \%)$ for the energy demand effect (Figure $8 \mathbf{b}$ and Table 3 ). The average annual contribution rates of the per capita consumption expenditure effect (energy demand effect) in the four stages were $3.63 \%$ $(-1.42 \%), 5.92 \%(2.95 \%), 10.55 \%(9.18 \%)$, and $8.87 \%(3.19 \%)$, respectively (Table 6). It can be seen that the driving effect of per capita consumption expenditure and energy demand on the total direct HCEs was increasing. However, their driving role declined in 2015-2017. The continued increase in residence expenditure has promoted the continued growth of HCEs directly. During 2000-2017, the per capita residence expenditure in Central China rose from CNY 290.11 to CNY 2064.30, an increase of $611.57 \%$, with an average annual growth rate of $12.24 \%$ (Figure 9c). The average annual growth rates were $5.32 \%, 9.77 \%$, $18.42 \%$, and $10.76 \%$, respectively in the four stages. The overall increase in household consumption level was also an essential reason for the rapid growth of direct HCEs in this region. Throughout the study period, the per capita consumption expenditure was up from CNY 2309.46 to CNY 10,087.93, an increase of $336.81 \%$, with an average annual growth rate of $9.06 \%$ (Figure $9 \mathrm{~b}$ ). The average yearly growth rates in the four phases were $8.62 \%$, $6.96 \%, 7.28 \%$, and $3.65 \%$, respectively. Therefore, people had the capacity to purchase more energy-intensive appliances and transportation tools, resulting in greater energy use. The number of air conditioners, refrigerators, and family cars owned per 100 households at the 2017 year-end were 95.22, 94.32, and 23.08, compared to 13.29, 43.44, and 0.18 in 2000 , with an increase of $616.48 \%, 117.13 \%$, and $12,722.22 \%$. Hence, it is vital to reduce the direct HCEs by limiting the growth of transportation tools and high energy-consuming appliances and improving energy use efficiency.

Population Size Effect and Population Urban-Rural Structure Effect

The population size effect and population urban-rural structure effect had less impact in promoting the direct HCEs in Central China during 2000-2017. The effects of population and population urban-rural structure, respectively, caused an increase of $1948.67 \times 10^{4}$ tonnes and $1354.44 \times 10^{4}$ tonnes with contribution rates of $9.4 \%$ and $6.54 \%$. In the four stages, the contribution values (rates) for the population effect were $318.37 \times 10^{4}$ tonnes $(1.54 \%), 790.83 \times 10^{4}$ tonnes $(3.82 \%), 532.04 \times 10^{4}$ tonnes $(2.57 \%)$, and $307.43 \times 10^{4}$ tonnes $(1.48 \%)$, respectively. The contribution values (rates) of population urban-rural structure effect were $387.37 \times 10^{4}$ tonnes $(1.87 \%), 473.62 \times 10^{4}$ tonnes $(2.29 \%)$, $43.05 \times 10^{4}$ tonnes $(0.21 \%)$, and $450.41 \times 10^{4}$ tonnes $(2.17 \%)$, respectively (Figure $8 \mathrm{~b}$ and Table 3). The average annual contribution rates of the population effect (population urbanrural structure effect) in the four stages were $0.31 \%(0.37 \%), 0.76 \%(0.46 \%), 0.51 \%(0.04 \%)$, and $0.74 \%(1.09 \%)$, respectively (Table 6$)$. The population growth of Central China played a certain role in promoting the increase of direct HCEs. The total population in Central China increased by $11.49 \%$ from $35,370.39 \times 10^{4}$ persons in 2000 to $39,434.67 \times 10^{4}$ persons in 2017, increasing energy demands and related emissions directly (Figure 9d). The average annual population growth rates in the four stages were $0.57 \%, 0.93 \%, 0.46 \%$, and $0.56 \%$, respectively.

There are two reasons why the population urban-rural structure showed a positive effect. One was that the per capita direct HCEs in urban areas were all higher than those in rural; the other was that the proportion of urban population continued to rise, and the urbanization rate kept increasing, owing to the continuous urbanization process. The urban population ratio rose by $63.80 \%$ from $28.22 \%$ in 2000 to $46.23 \%$ in 2017 , with an average 
annual growth rate of $2.95 \%$ (Figure $9 \mathrm{~d}$ ). The average annual growth rates were $3.73 \%$, $3.31 \%, 1.41 \%$, and $3.97 \%$ for each of the four stages, respectively.

\section{Energy Structure Effect}

The energy structure effect played a minor role in increasing the direct HCEs, which contributed $1743.56 \times 10^{4}$ tonnes $\mathrm{CO}_{2}$ over this 17 -year period and the contribution rate was $8.41 \%$. Specifically, the contribution values (rates) at each of the four stages were $603.48 \times 10^{4}$ tonnes $(2.91 \%), 935.23 \times 10^{4}$ tonnes $(4.51 \%),-409.25 \times 10^{4}$ tonnes $(-1.97 \%)$, and $614.10 \times 10^{4}$ tonnes $(2.96 \%)$, respectively (Figure $8 \mathrm{~b}$ and Table 3 ). The corresponding average annual contribution rates of the energy structure effect were $0.58 \%, 0.90 \%,-0.39 \%$, and $1.48 \%$, respectively (Table 6). It should be particularly noted that the growth of direct HCEs was inhibited during 2010-2015. The reason could be that the energy structure was being optimized in Central China at this period, which reduced $\mathrm{CO}_{2}$ emissions. As mentioned above, it was clear that $\mathrm{CO}_{2}$ emissions from coal use were gradually falling, while emissions from oil, natural gas, heat, and electricity were rising. China is constrained by coal-based resource endowments and the production of electricity and heat are also based on coal as the primary raw material. Consequently, coal is used in great quantities. Therefore, the government should strengthen the encouragement and support for developing non-fossil fuel energy sources such as wind energy, nuclear power, biomass, solar energy, and other clean energy. Natural gas is also a relatively low-carbon emitting energy of fossil fuels. At the same time, the consumption share of natural gas has been low due to the relatively underdeveloped economic conditions in Central China. Therefore, the natural gas industry should be strongly supported in this region, especially in rural areas, so that natural gas can be widely used. It is also an issue worthy of attention in the decarbonization of household consumption.

\subsubsection{Urban-Rural Differences}

The decomposition results of direct HCEs from urban and rural areas during 2000-2017 are presented in Tables 4 and 5. The same drivers affected urban and rural areas differently. As a whole, the energy structure effect, energy demand effect, per capita consumption expenditure effect, and population effect all contributed to the growth of direct HCEs in both urban and rural areas during 2000-2017 (Figure 10). The effects' contribution of the energy structures and per capita consumption expenditure contributed more to rural compared with urban areas. In 2017, these drivers increased direct HCEs by $72.07 \%$ and $54.53 \%$ in rural and urban areas. Conversely, the effects of energy demand and population in urban areas were greater than that in rural, which increased by $45.42 \%$ and $23.88 \%$ of total $\mathrm{CO}_{2}$ emissions. The energy price effect was negative for urban and rural direct HCEs, with cumulative contribution rates of $-61.70 \%$ and $-40.74 \%$, respectively.

The differences in drivers between urban and rural areas can be explained by different change rates of various influencing factors. For example, the difference in the magnitude of the energy price effect can be explained by the variation in the average energy prices for urban and rural areas. The energy prices rose from $0.44 \times 10^{4} \mathrm{CNY} /$ tce and $0.52 \times 10^{4}$ $\mathrm{CNY} /$ tce in 2000 to $1.11 \times 10^{4} \mathrm{CNY} /$ tce and $0.93 \times 10^{4} \mathrm{CNY} /$ tce in 2017 for urban and rural regions, respectively. In terms of the growth rate, compared to 2000 , it was $153.95 \%$ for urban areas and $78.69 \%$ for rural (Figure 11a). The change rates of per capita consumption expenditure for urban and rural areas were $228.31 \%$ and $344.13 \%$, respectively (Figure $11 b$ ). The growth rate of urban energy demand was higher than that of rural areas during the study period, as depicted in Figure 11c. The energy demand of urban and rural areas rose from $11.59 \%$ and $13.54 \%$ to $19.39 \%$ and $22.26 \%$, with the growth rates of $67.29 \%$ and $64.44 \%$, respectively (Figure 11c). The population urban-rural structure effect promoted the growth of direct HCEs in urban areas, whereas the opposite was true for rural. The contribution rates for urban and rural areas were $34.05 \%$ and $-31.46 \%$, respectively. By 2017 , the ratio of urban and rural population increased by $63.8 \%$ and $-25.1 \%$ than that in 2000 (Figure 11d). 


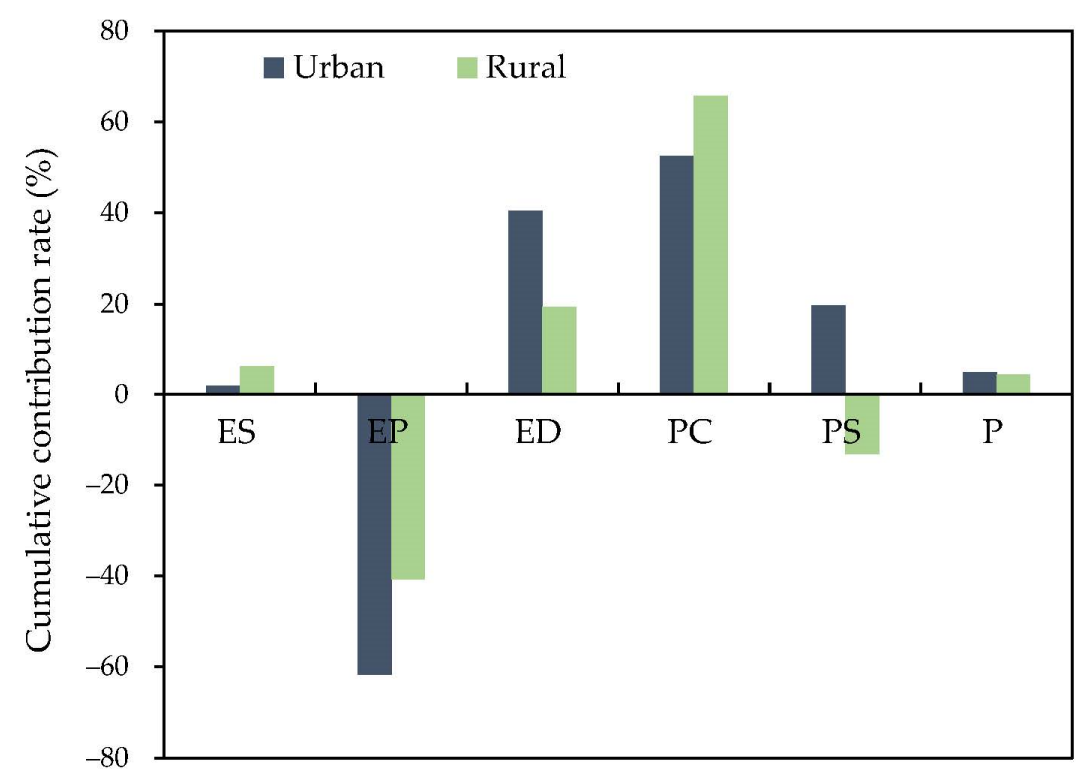

Figure 10. The cumulative contribution of decomposition factors of direct HCEs between urban and rural areas in Central China.

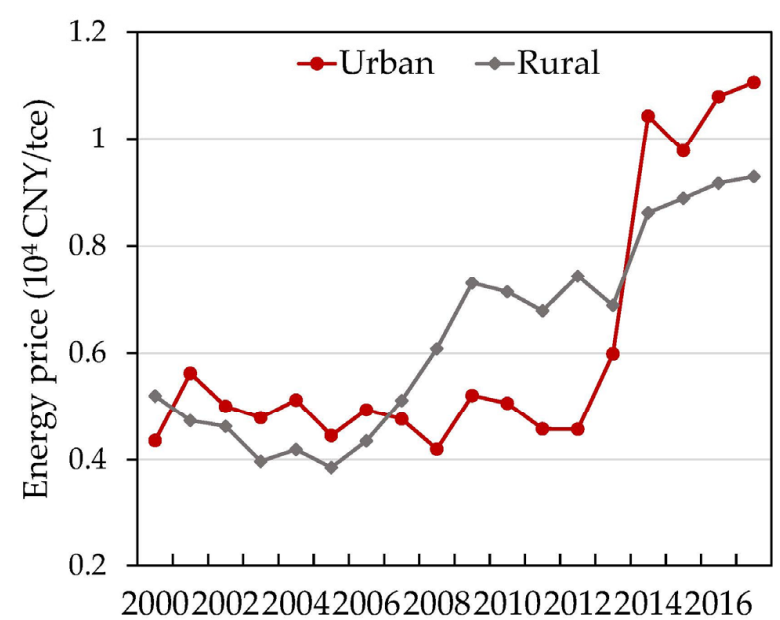

(a)

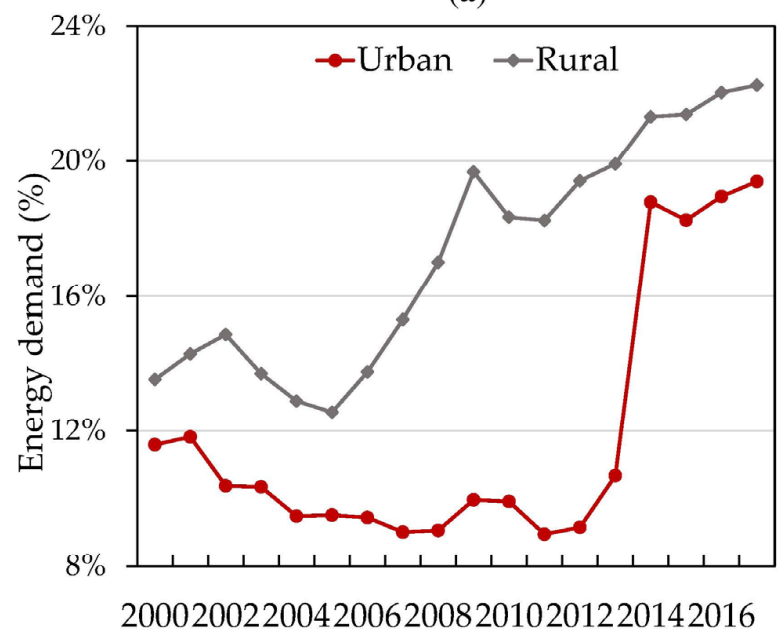

(c)

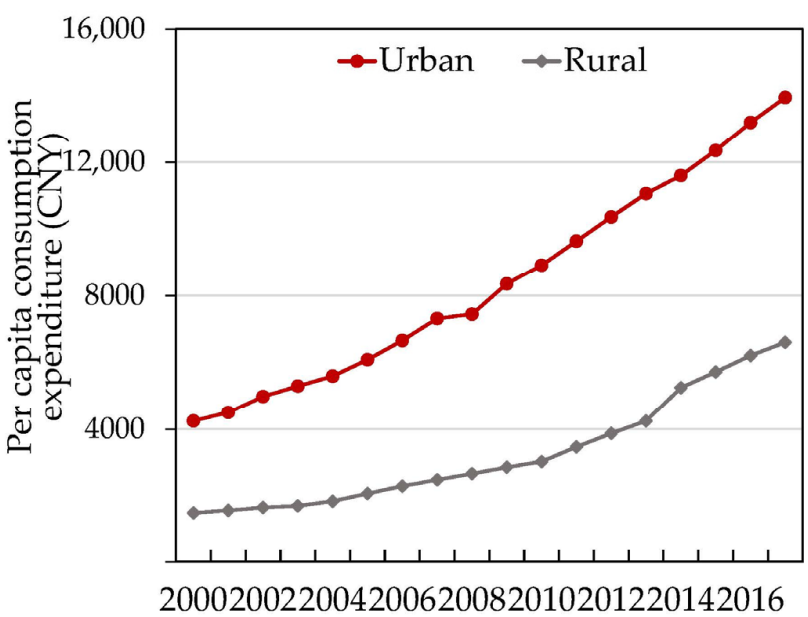

(b)

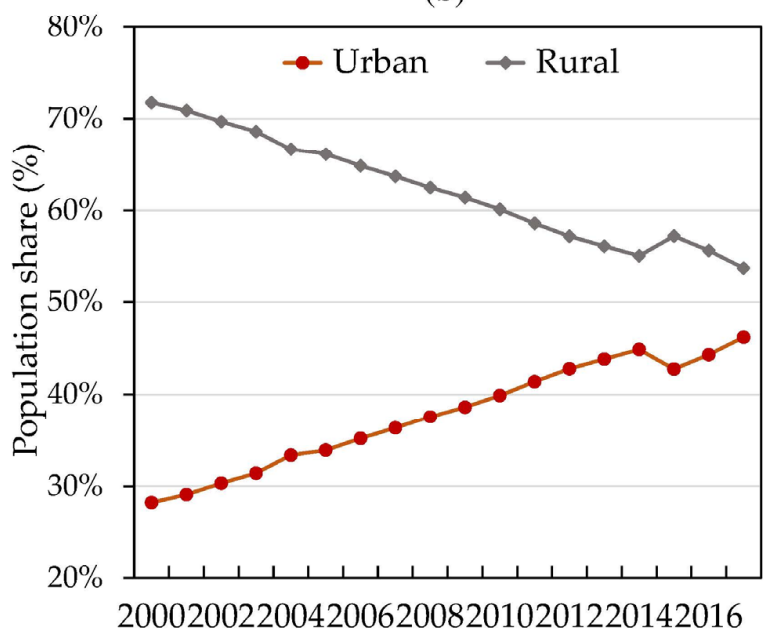

(d)

Figure 11. The variation trend of various influencing factors of direct HCEs in urban and rural areas in Central China. (a) Energy price; (b) Per capita consumption expenditure; (c) Energy demand; (d) Population share. 
In short, the two drivers with the greatest degree of influence on direct HCEs in rural areas were the effects of per capita consumption expenditure and energy demand, cumulatively contributing $85.14 \%$ of total HCEs. The population urban-rural structure effect and energy price effect reduced $53.96 \%$ of total direct HCEs. In urban areas, the two factors that contributed most to direct HCEs were also the per capita consumption expenditure and energy demand, contributing about $92.95 \%$ of direct HCEs. The change of energy price in urban areas mitigated the direct HCEs by $61.70 \%$.

\subsubsection{Inter-Provincial Comparison}

The cumulative contributions of various drivers to the HCEs for each province are exhibited in Figure 12, and the inter-provincial differences are noticeable.

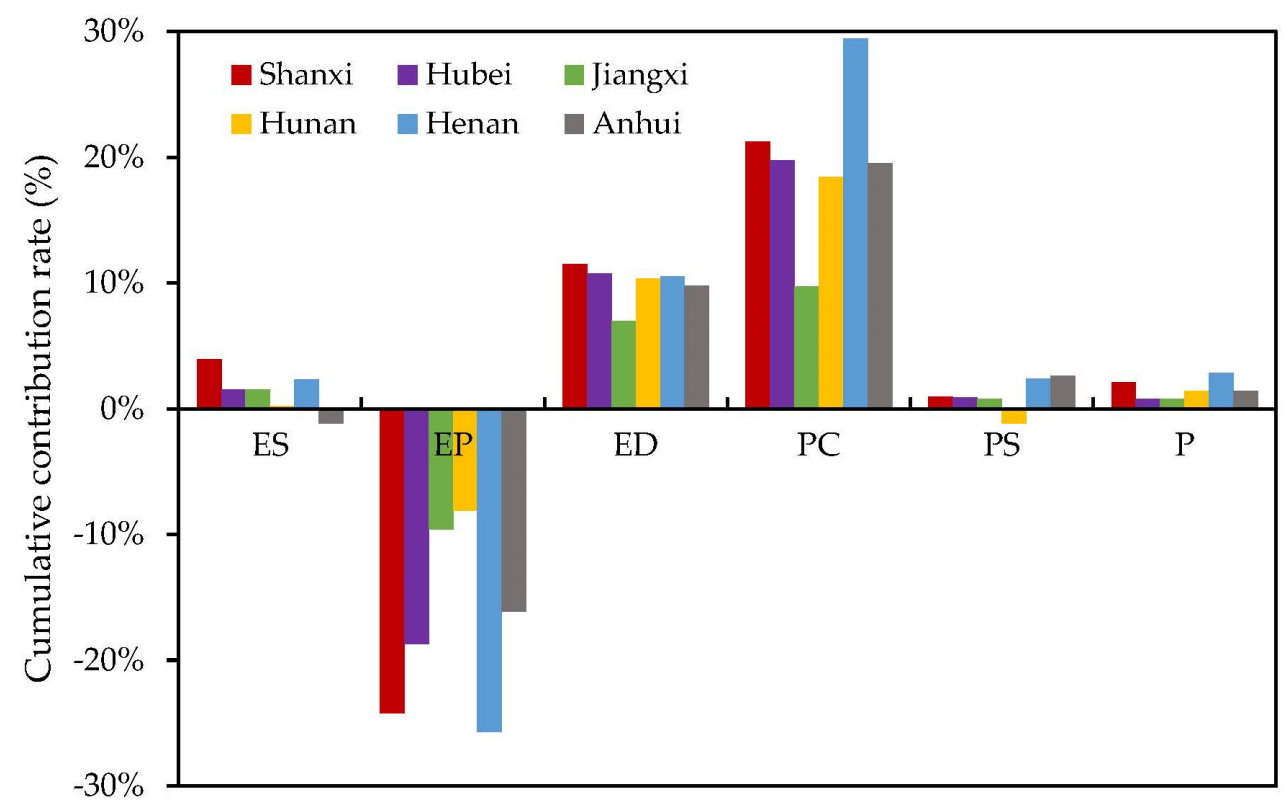

Figure 12. The cumulative contribution of different decomposition factors by province in Central China.

The energy price effect mitigated the growth of direct HCEs in all six provinces from 2000-2017. The absolute value of cumulative contribution of Henan Province was the largest $(25.70 \%)$, followed by Shanxi $(24.21 \%)$. The variation of energy prices in Hunan mitigated the smallest direct HCEs $(8.11 \%)$. This could be explained by the prominent gap of the change rate in average energy prices among provinces. The energy prices of Hunan, Anhui, Jiangxi, Hubei, Henan, and Shanxi increased by $21.86 \%, 117.46 \%, 125.17 \%, 155.55 \%$, $197.57 \%$, and $272.10 \%$, respectively (Figure 13a). The more energy prices rise, the stronger the contribution to carbon reduction will be. Therefore, Hunan Province had the largest flexibility to increase energy prices, while the opposite was true for Henan Province. It indicated that Hunan has a greater potential to reduce the direct HCEs by raising energy prices relative to Henan.

The per capita consumption expenditure effect boosted the growth of direct HCEs in all provinces. The largest contribution to direct HCEs was found in Henan, with a contribution rate of $29.44 \%$. Conversely, the change of the per capita consumption expenditure in Jiangxi contributed the least direct HCEs (9.72\%). Shanxi, Hubei, Anhui, and Hunan, whose contribution rates were $21.26 \%, 19.75 \%, 19.55 \%$, and $18.46 \%$, respectively. From 2000-2017, the per capita consumption expenditure in Shanxi Province and Jiangxi Province increased by $390.89 \%$ and $361.05 \%$, while Hunan Province increased by only $251.65 \%$ (Figure 13b). It can be seen that the difference in the per capita consumption expenditure effect was mainly caused by the change of the per capita consumption expenditure for each province. 


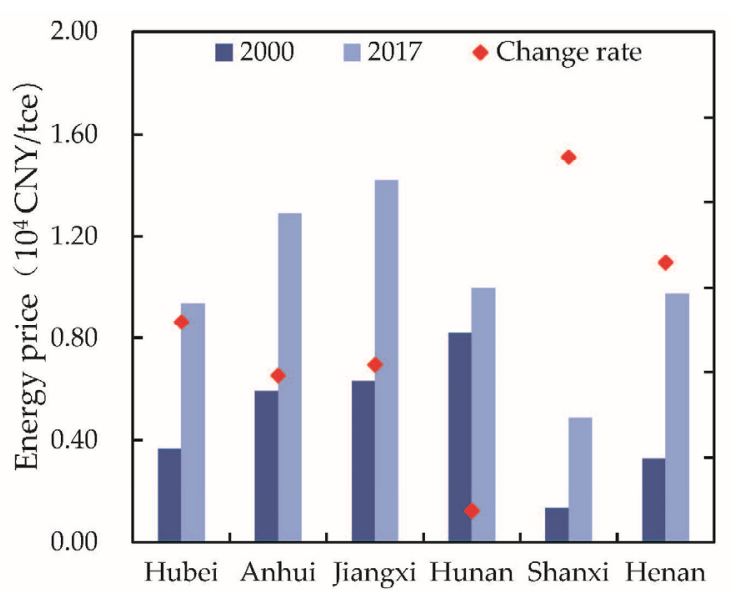

(a)

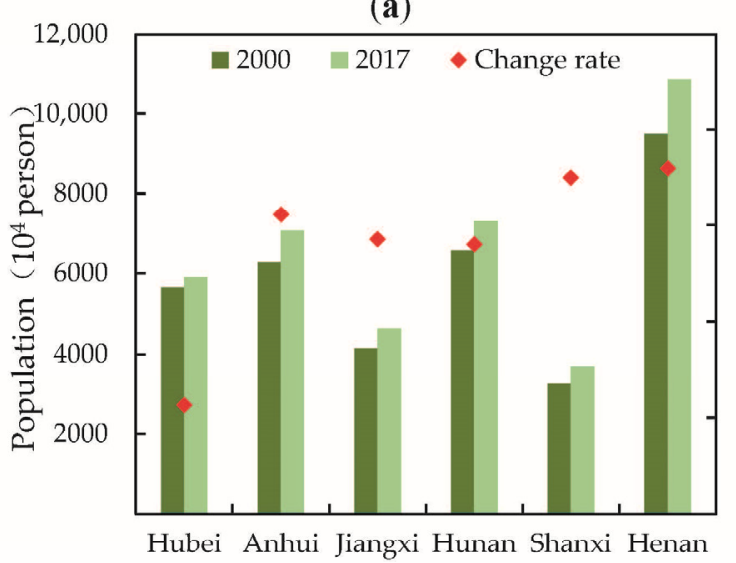

(c)

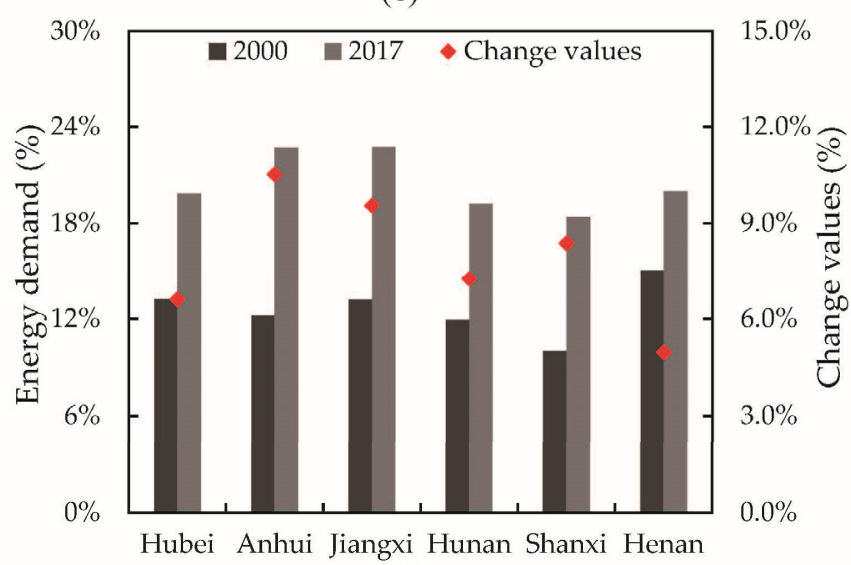

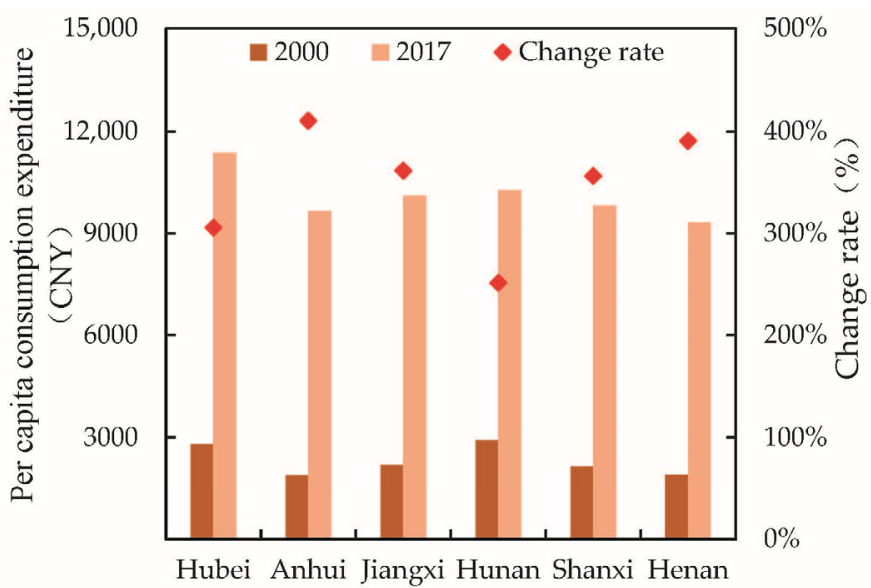

(b)

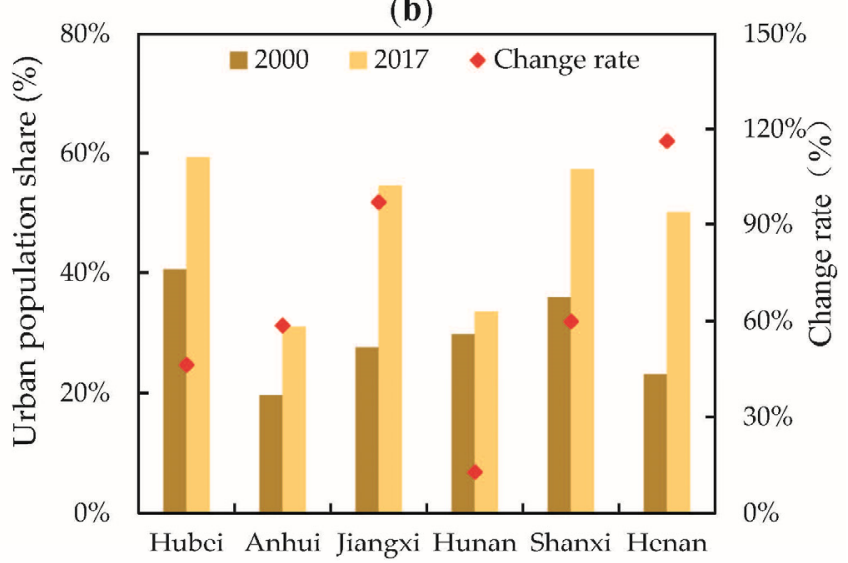

(d)

(e)

Figure 13. Variation of various influencing factors of direct HCEs in six provinces from 2000-2017. (a) Energy price; (b) Per capita consumption expenditure; (c) Population size; (d) Urban population share; (e) Energy demand.

The population effect likewise contributed the most strongly to direct HCEs in Henan Province, followed by Shanxi, with cumulative contribution rates of $2.88 \%$ and $2.12 \%$, respectively. The pulling effect on direct HCEs was more remarkable than in the other four provinces (Hunan, Jiangxi, Hubei, and Anhui). The population effect made the smallest contribution to Jiangxi, by only $0.76 \%$. From 2000 to 2017, the population of Henan, Shanxi and Jiangxi provinces was increasing year by year. The largest growth rate of population was $14.39 \%$ in Henan, and the growth rates of population of Shanxi, Anhui, Hunan, Hubei, and Jiangxi were $14.00 \%, 12.44 \%, 11.18 \%, 4.53 \%$, and $11.41 \%$, respectively (Figure $13 \mathrm{c}$ ), indicating that the gap of population growth was responsible for the difference of the population effect in the six provinces. 
The energy structure effect was only negative in Anhui Province, with a cumulative contribution rate of $-1.15 \%$ during 2000-2017. This can be explained by the change of energy structure in Anhui reduced the direct HCEs overall. Conversely, the energy structure effect in Shanxi contributed the highest direct HCEs (3.94\%), indicating that the shift in Shanxi's energy structure was most unfavorable to the reduction of direct HCEs. Therefore, it is more imperative for Shanxi to adjust the energy structure effectively by reducing the use of fossil energy such as coal and oil and accelerating the development of non-fossil energy sources such as wind energy and nuclear power.

The population urban-rural structure effect only showed a negative effect on direct HCEs in Hunan Province. The contribution rate of the population urban-rural structure effect varied significantly between provinces from 2000-2017. The aggregate contribution of the population urban-rural structure effect in Anhui Province was the highest at 2.64\%, followed by Henan Province (2.39\%), and Hunan Province had the lowest cumulative contribution of $-1.15 \%$. It can be derived that the change of population urban-rural structure in Hunan Province was generally beneficial to mitigating the direct HCEs. In the survey period, the share of urban population in Henan province increased from $23.20 \%$ to $50.16 \%$, with an increase of $116.23 \%$, while the proportion of urban population in Hunan province increased from $29.75 \%$ to $33.54 \%$, with a growth rate of only $12.73 \%$ (Figure $13 \mathrm{~d}$ ). Thus, it can be seen that the inter-provincial differences in the contribution of population urban-rural structure effect were mainly caused by the different change rates of the urban population share in each province.

The energy demand effect showed the strongest impact on the direct HCEs growth in Shanxi Province (11.51\%), and the smallest impact on the increment of direct HCEs in Jiangxi Province (6.97\%). The effect of energy demand in Hubei, Henan, Hunan, and Anhui contributed $10.74 \%, 10.52 \%, 10.36 \%$, and $9.81 \%$ to total change of direct HCEs, respectively (Figure 12). Energy demand in Shanxi Province increased from $10.01 \%$ in 2000 to $18.39 \%$ in 2017 , with a growth rate of $83.65 \%$. The change rates of energy demand in Hubei, Henan, Hunan, Anhui, and Jiangxi were $49.89 \%, 33.04 \%, 60.71 \%, 86.15 \%$, and $72.39 \%$, respectively (Figure 13e). This difference was mainly due to the different extent of variation in the share of residential energy consumption between provinces.

\section{Conclusions and Suggestions}

\subsection{Main Conclusions}

Taking Central China in the 2000-2017 years as an example, we analyzed the characteristics and driving factors of the direct HCEs from three perspectives. The urban-rural differences and inter-provincial comparison were highlighted. The conclusions are set out below.

From 2000 to 2017, total direct HCEs increased at an average annual growth of $7.00 \%$ from $9596.20 \times 10^{4}$ tonnes to $30,318.35 \times 10^{4}$ tonnes. Electricity and coal consumption were the primary sources. The direct HCEs in both urban and rural rose continuously. The growth amount and rate of urban direct HCEs were all higher than those from rural areas. The urban-rural gap of direct HCEs narrowed during 2000-2006 and then widened after 2006. There were also significant differences in the structure of direct HCEs between urban and rural areas. The share of $\mathrm{CO}_{2}$ emissions generated by coal consumption in rural areas was higher than that in urban, whereas $\mathrm{CO}_{2}$ emissions from oil, natural gas, heat, and electricity use were the opposite. From the perspective of inter-provincial comparison, the direct HCEs in the six provinces were all on the rise, while the growth rate and amount differed significantly. Among these, Henan, Shanxi, Hubei, Hunan, Anhui, and Jiangxi occupied $24.71 \%, 18.52 \%, 17.12 \%, 15.98 \%, 15.11 \%$, and $8.56 \%$, respectively, in the order of cumulative value. The difference in the amount of direct HCEs among provinces was decreasing.

Overall, the effects' contribution of energy structure, energy price, energy demand, per capita consumption expenditure, population urban-rural structure and population were $8.41 \%,-102.44 \%, 59.90 \%, 118.19 \%, 6.54 \%$, and $9.40 \%$, respectively. The results indicated 
that the growth in per capita consumption expenditure was the most prominent driver behind the increase of direct HCEs in Central China, followed by energy demand. The effects of population size, energy structure and population urban-rural structure had less impact on the growth of direct HCEs. However, energy price presented the most obvious mitigation effect. From the perspective of urban-rural differences, the effects of per capita consumption expenditure and energy structure had a greater impact on direct HCEs in rural areas than in urban among the contributing factors, whereas the energy demand effect and the population size effect were the opposite. The energy price effect was the greater disincentive on urban areas than on rural. The effect of population urban-rural structure promoted the growth of direct HCEs in urban areas, whereas the opposite was true for rural. There were also some variabilities in the extent to which the same driving factor affected different provinces.

\subsection{Discussion}

It would be meaningful to compare the results of this paper with previous studies. First of all, the direct HCEs had an obvious growth trend in Central China, with an average annual growth of $7.00 \%$. On the other hand, the direct HCEs of China increased by 51,883 $\times 10^{4}$ tonnes during 1996-2012 [19], and the direct HCEs in China grew at an average annual rate of $7 \%$ from 2000-2015 [40]. Therefore, it can be seen that the growth rate of total direct HCEs in Central China is similar to that of the whole of China. Additionally, coal and electricity consumption were the main sources of HCEs. The cumulative share of $\mathrm{CO}_{2}$ emissions from electricity and coal during 2000-2017 accounted for $46.55 \%$ and $34.99 \%$ of the total HCEs in Central China. Nationally, the total share of $\mathrm{CO}_{2}$ emissions from coal and electricity ranged from $45.7 \%$ to $61.4 \%$ [45]. Moreover, the direct HCEs and growth rate in urban areas were higher than those in rural areas, and the urban-rural differences were significant, which was in line with Li et al. [19] and Feng et al. [33]. From a single year, the direct HCEs in Central China were 26,535.65 $\times 10^{4}$ tonnes in 2015, accounting for approximately $22.85 \%$ of the national direct HCEs (11,6120 $\times 10^{4}$ tonnes) [40].

The LMDI decomposition analysis was then applied to investigate the factors that might affect the changes of the direct HCEs. The decomposition results in Central China were similar to those of Zha et al. in the whole of China [45]. They both indicated that the energy price (energy intensity) and per capita consumption expenditure (income) effects contributed most to the decline and the increase of $\mathrm{CO}_{2}$ emissions, respectively. Other factors had less impact on the growth of $\mathrm{CO}_{2}$ emissions. However, our decomposition results differed from those in Guangdong Province [35]. The first promoting factor to HCEs in Guangdong were population size (1996-2004) and energy use level (2005-2016). The carbon emission coefficient was the main inhibiting factor. This fact could be explained by the differences in the level of economic development and resource endowments between regions.

In addition, there are some limitations in this paper. Only six driving factors affecting the direct HCEs in Central China were explored, specifically energy structure, per capita consumption expenditure, energy price, energy demand, population urban-rural structure, and population size. However, direct HCEs may be influenced by the number of households [48], temperature, Engel coefficient [30], demographic structure [48], and other socioeconomic factors. Thus, in our future work, these factors to the direct HCEs should be given greater attention.

\subsection{Suggestions}

Based on these results, some particular countermeasures and suggestions for sustainable household energy consumption of Central China are put forward and listed as follows.

First, the energy prices should be adjusted appropriately. The energy price effect was the biggest factor in mitigating the direct HCEs. It indicated that the deregulation of energy prices in the above text was an effective scientific way to realize energy conservation 
and emission reduction. The corresponding energy prices need to be further adjusted by government appropriately, especially the price of energy with a high emission coefficient. The six provinces should develop different policies for adjusting energy prices based on respective development characteristics, particularly those provinces that are greatly affected by fluctuations in energy price, such as Hunan Province, which needs to raise energy prices appropriately.

Additionally, the residents' consumption should be upgraded to a green and sustainable pattern. The effect of per capita consumption expenditure had the most impact on the growth of direct HCEs in Central China. With the development of economy and the improvement of residents' living standard, the government should advocate the shift of residents' consumption patterns to green and sustainable, and reasonably control the growth rate of transportation and energy-intensive devices. Some measures can be implemented. For example, the charging model of residential energy consumption needs to be adjusted, the energy-saving standards for household appliances need to be popularized, and the energy-saving behavior patterns need to be promoted and publicized with the aid of the media.

Next, population size and low-carbon urbanization should be reasonably controlled. The growth of direct HCEs in Central China has been less influenced by population size and population urban-rural structure. However, the net population continues to rise due to the large population base and the liberalization of the three-child policy in this region. Consequently, the government should control population growth within a reasonable range. This is particularly true for provinces with a large population, such as Henan Province. In addition, the urban pattern should be scientifically designed in the process of urbanization, and the development of low-carbon infrastructure should be encouraged. Meanwhile, raising people's awareness of energy conservation is an important goal in the cultivation of urbanized humanities. The urbanization can be developed along the new direction of intensive, green and low-carbon.

Lastly, the household energy structure should be optimized and the development and use of clean energy should be accelerated. Greater efforts should be made to optimize the household energy structure by reducing the use of coal and developing the use of natural gas, especially in rural areas, and encouraging the use of renewable energy. From the perspective of the emission structure of each province, the modification of Anhui's energy structure was most conducive to the reduction of $\mathrm{CO}_{2}$ emissions. Shanxi Province needs to cut the use of fossil energy such as coal and oil, and accelerate the development of non-fossil fuel energy such as wind and nuclear, in comparison to other the five provinces.

Author Contributions: Conceptualization, Y.R. and J.J.; investigation, M.J. and C.C.; data curation Y.Z. (Yangming Zhou); methodology, Y.Z. (Yangming Zhou) and Y.Z. (Yexi Zhong); writing—original draft preparation, Y.R.; writing-review and editing, J.J. All authors have read and agreed to the published version of the manuscript.

Funding: This research was funded by the Research Project of Humanities and Social Science in Jiangxi's Universities (Grant No. GL.19225) and the Chinese National Science Foundation (Grant No. 71473113).

Institutional Review Board Statement: Not applicable.

Informed Consent Statement: Not applicable.

Data Availability Statement: The data presented in this study are available on request from the corresponding author.

Acknowledgments: We thank the anonymous reviewers and editors for their constructive comments and suggestions to improve the quality of this article.

Conflicts of Interest: The authors declare no conflict of interest. 


\section{Appendix A}

Table A1. Carbon emission coeffcients and standard coal coefficients for each energy type.

\begin{tabular}{ccc}
\hline Energy Type & $\begin{array}{c}\text { Emission Coefficient } \\
\left(\mathbf{t}-\mathbf{C O}_{\mathbf{2}} / \mathbf{t}\right)\end{array}$ & $\begin{array}{c}\text { Standard Coal Coefficient } \\
\text { (Kg ce/kg) }\end{array}$ \\
\hline Raw coal & 1.977 & 0.7143 \\
Cleaned coal & 2.488 & 0.9000 \\
Other washed coal & 0.795 & 0.2857 \\
Briquettes & 1.717 & 0.6000 \\
Coke & 3.019 & 0.9714 \\
Coke oven gas & $7.421^{1}$ & $0.5714^{2}$ \\
Blast furnace gas & $3.019^{1}$ & $0.1286^{2}$ \\
Converter gas & $3.524^{1}$ & $0.2714^{2}$ \\
Other gas & $2.319^{1}$ & $0.1786^{2}$ \\
Gasoline & 3.185 & 1.4714 \\
Kerosene & 3.153 & 1.4714 \\
Fuel oil & 3.126 & 1.4286 \\
Diesel oil & 3.185 & 1.4571 \\
Lubricants & 2.948 & 1.4143 \\
Bitumen asphalt & - & 1.3100 \\
Refinery gas & 2.983 & 1.7143 \\
Liquefied petroleum gas (LPG) & 2.850 & 1.5714 \\
Other petroleum products & 2.948 & 1.2000 \\
Natural gas & $21.840^{1}$ & $1.3300^{2}$ \\
Liquefied natural nas (LNG) & 2.836 & 1.7572 \\
\hline
\end{tabular}

${ }^{1}$ The unit is $\mathrm{t}-\mathrm{CO}_{2} / 10^{4} \mathrm{~m}^{3},{ }^{2}$ the unit is $\mathrm{Kg} \mathrm{ce} / \mathrm{m}^{3}$.

Table A2. Average $\mathrm{CO}_{2}$ emission factor per unit of power supply in six central provinces.

\begin{tabular}{lcccccc}
\hline Province & Shanxi & Henan & Anhui & Hubei & Hunan & Jiangxi \\
\hline Emission coefficient & 1.246 & 0.801 & 0.928 & 0.801 & 0.801 & 0.801 \\
\hline Note: The unit is $\mathrm{kg} / \mathrm{kw} \cdot \mathrm{h}$. & & & & & &
\end{tabular}

Table 3. Decomposition results of direct HCEs in Central China ( $10^{4}$ tonnes).

\begin{tabular}{cccccccc}
\hline Periods & $\Delta C_{E S}$ & $\Delta C_{E P}$ & $\Delta C_{E D}$ & $\Delta C_{P C}$ & $\Delta C_{P S}$ & $\Delta C_{P}$ & $\Delta C_{T O T}$ \\
\hline $2000-2001$ & 202.20 & -921.04 & 299.34 & 513.11 & 86.35 & 60.16 & 240.12 \\
$2001-2002$ & 85.23 & -142.38 & -258.34 & 826.14 & 79.40 & 59.04 & 649.08 \\
$2002-2003$ & 137.37 & 622.70 & -570.99 & 470.91 & 81.67 & 59.06 & 800.73 \\
$2003-2004$ & 241.47 & -220.50 & -678.76 & 707.93 & 102.12 & -213.81 & -61.56 \\
$2004-2005$ & -62.79 & 1044.13 & -263.93 & 1239.81 & 37.83 & 353.92 & 2348.98 \\
$2005-2006$ & 398.85 & -2087.24 & 738.53 & 1441.12 & 111.31 & 72.00 & 674.56 \\
$2006-2007$ & 84.63 & -1442.48 & 514.79 & 1363.59 & 76.03 & 83.08 & 679.63 \\
$2007-2008$ & 0.94 & -421.79 & 918.81 & 734.18 & 76.64 & 86.05 & 1394.83 \\
$2008-2009$ & 285.09 & -2175.40 & 1749.22 & 1475.69 & 63.05 & 91.75 & 1489.40 \\
$2009-2010$ & 165.72 & 168.09 & -869.38 & 1116.36 & 146.59 & 457.95 & 1185.32 \\
$2010-2011$ & -22.13 & 1197.31 & -1149.62 & 2108.72 & 116.51 & 117.77 & 2368.55 \\
$2011-2012$ & 54.67 & -876.57 & 860.86 & 2115.31 & 75.67 & 105.83 & 2335.77 \\
$2012-2013$ & -106.05 & -3292.00 & 1581.21 & 1818.44 & 57.90 & 73.38 & 132.87 \\
$2013-2014$ & -351.91 & $-10,702.11$ & 8549.70 & 3095.71 & 42.55 & 110.96 & 744.90 \\
$2014-2015$ & 16.18 & 608.76 & -331.13 & 1787.93 & -249.58 & 124.09 & 1956.25 \\
$2015-2016$ & 793.38 & -2316.14 & 893.60 & 1982.69 & 200.02 & 202.59 & 1756.15 \\
$2016-2017$ & -179.28 & -271.70 & 429.13 & 1693.17 & 250.39 & 104.84 & 2026.55 \\
$2000-2017$ & 1743.56 & $-21,228.36$ & $12,413.03$ & $24,490.81$ & 1354.44 & 1948.67 & $20,722.15$ \\
$2000-2005$ & 603.48 & 382.90 & -1472.68 & 3757.91 & 387.37 & 318.37 & 3977.36 \\
$2005-2010$ & 935.23 & -5958.82 & 3051.96 & 6130.93 & 473.62 & 790.83 & 5423.75 \\
$2010-2015$ & -409.25 & $-13,064.61$ & 9511.01 & $10,926.11$ & 43.05 & 532.04 & 7538.34 \\
$2015-2017$ & 614.10 & -2587.84 & 1322.74 & 3675.86 & 450.41 & 307.43 & 3782.70 \\
\hline
\end{tabular}


Table 4. Decomposition results of direct HCEs of urban areas in Central China ( $10^{4}$ tonnes).

\begin{tabular}{cccccccc}
\hline Periods & $\Delta C_{E S}$ & $\Delta C_{E P}$ & $\Delta C_{E D}$ & $\Delta C_{P C}$ & $\Delta C_{P S}$ & $\Delta C_{P}$ & $\Delta C_{T O T}$ \\
\hline $2000-2001$ & 48.92 & -884.94 & 87.95 & 262.40 & 123.45 & 28.93 & -333.28 \\
$2001-2002$ & 141.23 & 225.20 & -478.95 & 481.18 & 203.33 & 27.99 & 599.99 \\
$2002-2003$ & 130.84 & -267.89 & -30.27 & 308.34 & 167.64 & 28.14 & 336.80 \\
$2003-2004$ & 49.52 & 100.53 & -394.98 & 271.66 & 318.20 & -108.96 & 235.98 \\
$2004-2005$ & -148.32 & 715.31 & -76.85 & 534.35 & 73.40 & 192.97 & 1290.86 \\
$2005-2006$ & 201.34 & -784.87 & -78.79 & 645.89 & 254.15 & 36.44 & 274.16 \\
$2006-2007$ & 6.97 & -200.89 & -248.05 & 713.16 & 219.61 & 42.51 & 533.31 \\
$2007-2008$ & -137.76 & 253.95 & 174.39 & 223.95 & 239.16 & 44.09 & 797.77 \\
$2008-2009$ & 153.52 & -1019.54 & 626.42 & 883.02 & 217.87 & 46.60 & 907.89 \\
$2009-2010$ & -130.81 & 104.27 & -128.33 & 637.04 & 361.30 & 227.70 & 1071.17 \\
$2010-2011$ & -41.60 & 924.27 & -1170.68 & 889.20 & 383.71 & 64.16 & 1049.05 \\
$2011-2012$ & -24.71 & -272.24 & 198.24 & 864.27 & 368.42 & 55.47 & 1189.45 \\
$2012-2013$ & 78.01 & -2292.42 & 1487.86 & 795.20 & 288.59 & 40.45 & 397.69 \\
$2013-2014$ & -249.94 & -8300.18 & 7864.60 & 679.59 & 274.03 & 60.25 & 328.35 \\
$2014-2015$ & 37.81 & 989.25 & -370.34 & 838.92 & -662.77 & 67.34 & 900.20 \\
$2015-2016$ & 401.02 & -1862.68 & 634.05 & 955.90 & 562.38 & 106.04 & 796.71 \\
$2016-2017$ & -82.85 & -212.76 & 297.08 & 882.92 & 699.99 & 58.99 & 1643.38 \\
$2000-2017$ & 433.18 & $-12,785.62$ & 8393.35 & $10,866.99$ & 4092.47 & 1019.10 & $12,019.48$ \\
$2000-2005$ & 222.19 & -111.78 & -893.09 & 1857.93 & 886.02 & 169.07 & 2130.35 \\
$2005-2010$ & 93.26 & -1647.08 & 345.64 & 3103.05 & 1292.10 & 397.34 & 3584.30 \\
$2010-2015$ & -200.44 & -8951.32 & 8009.68 & 4067.18 & 651.98 & 287.66 & 3864.74 \\
$2015-2017$ & 318.17 & -2075.44 & 931.13 & 1838.82 & 1262.37 & 165.03 & 2440.09 \\
\hline
\end{tabular}

Table 5. Decomposition results of direct HCEs of rural areas in Central China ( $10^{4}$ tonnes).

\begin{tabular}{cccccccc}
\hline Periods & $\Delta C_{E S}$ & $\Delta C_{E P}$ & $\Delta C_{E D}$ & $\Delta C_{P C}$ & $\Delta C_{P S}$ & $\Delta C_{P}$ & $\Delta C_{T O T}$ \\
\hline $2000-2001$ & 153.27 & -36.10 & 211.39 & 250.71 & -37.10 & 31.24 & 573.40 \\
$2001-2002$ & -56.00 & -367.59 & 220.61 & 344.96 & -123.93 & 31.05 & 49.09 \\
$2002-2003$ & 6.53 & 890.59 & -540.72 & 162.57 & -85.96 & 30.93 & 463.93 \\
$2003-2004$ & 191.95 & -321.04 & -283.78 & 436.27 & -216.08 & -104.86 & -297.54 \\
$2004-2005$ & 85.54 & 328.82 & -187.07 & 705.46 & -35.58 & 160.95 & 1058.12 \\
$2005-2006$ & 197.51 & -1302.37 & 817.32 & 795.23 & -142.85 & 35.56 & 400.40 \\
$2006-2007$ & 77.66 & -1241.58 & 762.84 & 650.43 & -143.58 & 40.57 & 146.33 \\
$2007-2008$ & 138.70 & -675.74 & 744.42 & 510.24 & -162.52 & 41.96 & 597.07 \\
$2008-2009$ & 131.57 & -1155.86 & 1122.80 & 592.67 & -154.82 & 45.15 & 581.51 \\
$2009-2010$ & 296.53 & 63.82 & -741.05 & 479.31 & -214.71 & 230.25 & 114.14 \\
$2010-2011$ & 19.47 & 273.05 & 21.06 & 1219.52 & -267.20 & 53.61 & 1319.51 \\
$2011-2012$ & 79.38 & -604.33 & 662.62 & 1251.04 & -292.75 & 50.36 & 1146.32 \\
$2012-2013$ & -184.06 & -999.58 & 93.34 & 1023.25 & -230.69 & 32.93 & -264.82 \\
$2013-2014$ & -101.97 & -2401.93 & 685.10 & 2416.12 & -231.48 & 50.71 & 416.55 \\
$2014-2015$ & -21.62 & -380.49 & 39.21 & 949.00 & 413.19 & 56.76 & 1056.05 \\
$2015-2016$ & 392.36 & -453.46 & 259.56 & 1026.79 & -362.36 & 96.55 & 959.44 \\
$2016-2017$ & -96.44 & -58.94 & 132.05 & 810.25 & -449.60 & 45.85 & 383.17 \\
$2000-2017$ & 1310.37 & -8442.75 & 4019.67 & $13,623.82$ & -2738.03 & 929.57 & 8702.67 \\
$2000-2005$ & 381.29 & 494.68 & -579.59 & 1899.98 & -498.65 & 149.31 & 1847.01 \\
$2005-2010$ & 841.97 & -4311.74 & 2706.33 & 3027.88 & -818.48 & 393.49 & 1839.45 \\
$2010-2015$ & -208.81 & -4113.29 & 1501.33 & 6858.93 & -608.93 & 244.37 & 3673.61 \\
$2015-2017$ & 295.92 & -512.40 & 391.61 & 1837.04 & -811.96 & 142.40 & 1342.61 \\
\hline
\end{tabular}

\section{References}

1. IPCC. Climate Change 2007: IPCC Fourth Assessment Report; Cambridge University Press: Cambridge, UK, 2007.

2. IPCC. Climate Change 2013: The Physical Science Basis. Contribution of Working Group I to the Fifth Assessment Report of the Intergovernmental Panel on Climate Change; Cambridge University Press: Cambridge, UK, 2013.

3. Zeng, S.H.; Jia, J.M.; Su, B.; Jiang, C.X.; Zeng, G.W. The volatility spillover effect of the European Union (EU) carbon financial market. J. Clean. Prod. 2021, 282, 124394. [CrossRef] 
4. Zeng, S.H.; Jiang, X.; Su, B.; Nan, X. China's $\mathrm{SO}_{2}$ shadow prices and environmental technical efficiency at the province level. Int. Rev. Econ. Financ. 2018, 57, 86-102. [CrossRef]

5. $\quad$ BP. Statistical Review of World Energy, 63th ed.; BP: London, UK, 2014.

6. $\quad$ BP. Statistical Review of World Energy, 68th ed.; BP: London, UK, 2019.

7. Sun, M.M.; Wang, Y.T.; Shi, L.; Klemeš, J.J. Uncovering energy use, carbon emissions and environmental burdens of pulp and paper industry: A systematic review and meta-analysis. Renew. Sustain. Energy Rev. 2018, 92, 823-833. [CrossRef]

8. Huang, R.; Zhang, S.; Liu, C. Comparing Urban and Rural Household $\mathrm{CO}_{2}$ Emissions-Case from China's Four Megacities: Beijing, Tianjin, Shanghai, and Chongqing. Energies 2018, 11, 1257. [CrossRef]

9. Fan, J.L.; Yu, H.; Wei, Y.M. Residential energy-related carbon emissions in urban and rural China during 1996-2012: From the perspective of five end-use activities. Energy Build. 2015, 96, 201-209. [CrossRef]

10. Jiang, L.; Chen, X.; Xue, B. Features, Driving Forces and Transition of the Household Energy Consumption in China: A Review. Sustainability 2019, 11, 1186. [CrossRef]

11. Bin, S.; Dowlatabadi, H. Consumer lifestyle approach to US energy use and the related $\mathrm{CO}_{2}$ emissions. Energy Policy 2005, 33 , 197-208. [CrossRef]

12. Pachauri, S.; Spreng, D. Direct and indirect energy requirements of households in India. Energy Policy 2002, 30, 511-523. [CrossRef]

13. Baiocchi, G.; Minx, J.; Hubacek, K. The Impact of Social Factors and Consumer Behavior on Carbon Dioxide Emissions in the United Kingdom. J. Ind. Ecol. 2010, 14, 50-72. [CrossRef]

14. Park, H.C.; Heo, E. The direct and indirect household energy requirements in the Republic of Korea from 1980 to 2000-An input-output analysis. Energy Policy 2007, 35, 2839-2851. [CrossRef]

15. Liu, L.C.; Wu, G.; Wang, J.N.; Wei, Y.M. China's carbon emissions from urban and rural households during 1992-2007. J. Clean. Prod. 2011, 19, 1754-1762. [CrossRef]

16. Fan, J.L.; Liao, H.; Liang, Q.M.; Tatano, H.; Liu, C.F.; Wei, Y.M. Residential carbon emission evolutions in urban-rural divided China: An end-use and behavior analysis. Appl. Energy 2013, 101, 323-332. [CrossRef]

17. Wu, S.; Lei, Y.; Li, S. $\mathrm{CO}_{2}$ emissions from household consumption at the provincial level and interprovincial transfer in China. J. Clean. Prod. 2019, 210, 93-104. [CrossRef]

18. Dong, H.; Geng, Y. A study on the carbon footprint of residential consumption in Beijing based on input-output analysis. Res. Sci. 2012, 34, 494-501. (In Chinese)

19. Li, Y.; Zhao, R.; Liu, T.; Zhao, J. Does urbanization lead to more direct and indirect household carbon dioxide emissions? Evidence from China during 1996-2012. J. Clean. Prod. 2015, 102, 103-114. [CrossRef]

20. Mongelli, I.; Tassielli, G.; Notarnicola, B. Global warming agreements, international trade and energy/carbon embodiments: An input-output approach to the Italian case. Energy Policy 2006, 34, 88-100. [CrossRef]

21. Weber, C.; Matthews, H. Quantifying the global and distributional aspects of American household carbon footprint. Ecol. Econ. 2008, 66, 379-391. [CrossRef]

22. Larsen, H.; Hertwich, E. Analyzing the carbon footprint from public services provided by counties. J. Clean. Prod. 2011, 19, 1975-1981. [CrossRef]

23. Hertwich, E. Life Cycle Approaches to Sustainable Consumption: A Critical Review. Environ. Sci. Technol. 2005, 39, 4673-4684. [CrossRef]

24. Jia, J.; Gong, Z.; Chen, C.; Gu, Z.; Xie, D. Incorporating carbon emissions from landfills and wastewater treatment into a household emission inventory for systematically analysing household behaviour. J. Water. Clim. Chang. 2019, 10, 708-724. [CrossRef]

25. Zhang, X.; Luo, L.; Skitmore, M. Household carbon emission research: An analytical review of measurement, influencing factors and mitigation prospects. J. Clean. Prod. 2015, 10, 873-883. [CrossRef]

26. Dias, A.; Arroja, L. Comparison of methodologies for estimating the carbon footprint-Case study of office paper. J. Clean. Prod. 2012, 24, 30-35. [CrossRef]

27. Yang, Y.; Jia, J.; Chen, C. Residential Energy-Related $\mathrm{CO}_{2}$ Emissions in China's Less Developed Regions: A Case Study of Jiangxi. Sustainability 2020, 12, 2000. [CrossRef]

28. IPCC. IPCC Guidelines for National Greenhouse Gas Inventories; Cambridge University Press: Cambridge, UK, 2006.

29. Wei, Y.M.; Liu, L.C.; Fan, Y.; Wu, G. The impact of life style on energy use and $\mathrm{CO}_{2}$ emission: An empirical analysis of China's residents. Energy Policy 2007, 35, 247-257. [CrossRef]

30. Jin, X.; Li, Y.; Sun, D.; Zhang, J.; Zheng, J. Factors Controlling Urban and Rural Indirect Carbon Dioxide Emissions in Household Consumption: A Case Study in Beijing. Sustainability 2019, 11, 6563. [CrossRef]

31. Li, Q.; $\mathrm{Wu}, \mathrm{S}$.; Lei, $\mathrm{Y}$; $\mathrm{Li}, \mathrm{S}$. Dynamic features and driving forces of indirect $\mathrm{CO}_{2}$ emissions from Chinese household: A comparative and mitigation strategies analysis. Sci. Total Environ. 2020, 704, 135367. [CrossRef]

32. Leontief, W. Environmental Repercussions and the Economic Structure: An Input-Output Approach. Rev. Econ. Stat. 1970, 52, 262-271. [CrossRef]

33. Liu, J.; Peters, G.P.; Wang, R.; Yang, J. Application of Integrated Life Cycle Analysis in Sustainable Consumption Research. Acta Ecol. Sin. 2007, 27, 5331-5336. (In Chinese)

34. Feng, Z.H.; Zou, L.L.; Wei, Y.M. The impact of household consumption on energy use and $\mathrm{CO}_{2}$ emissions in China. Energy 2011, 36, 656-706. [CrossRef] 
35. Wang, W.; Zhao, D.; Kuang, Y. Decomposition analysis on influence factors of direct household energy-related carbon emission in Guangdong province-Based on extended Kaya identity. Environ. Prog. Sustain. 2016, 35, 298-307. [CrossRef]

36. Fan, J.; Ran, A.; Li, X. A Study on the Factors Affecting China's Direct Household Carbon Emission and Comparison of Regional Differences. Sustainability 2019, 11, 4919. [CrossRef]

37. Wang, L.; Qu, J.; Liu, L.; Bian, Y. Analysis and comparison of urban and rural household carbon emissions in China. J. Arid. Land Resour. Environ. 2015, 29, 6-11. (In Chinese)

38. Zhou, X.Y.; Gu, A.L. Impacts of household living consumption on energy use and carbon emissions in China based on the input-output model. Adv. Clim. Chang. Res. 2020, 11, 118-130. [CrossRef]

39. Ding, Y.; Qu, W.; Niu, S.; Liang, M.; Qiang, W.; Hong, Z. Factors Influencing the Spatial Difference in Household Energy Consumption in China. Sustainability 2016, 8, 1285. [CrossRef]

40. Shi, Y.; Han, B.; Han, L.; Wei, Z. Uncovering the national and regional household carbon emissions in China using temporal and spatial decomposition analysis models. J. Clean. Prod. 2019, 232, 966-979. [CrossRef]

41. Zhang, H.; Lahr, M.L. Households' Energy Consumption Change in China: A Multi-Regional Perspective. Sustainability 2018, 10, 2486. [CrossRef]

42. Li, J.; Huang, X.; Yang, H.; Chuai, X.; Li, Y.; Qu, J. Situation and determinants of household carbon emissions in Northwest China. Habitat Int. 2016, 51, 178-187. [CrossRef]

43. Zheng, S.; Wang, R.; Glaeser, E.L.; Kahn, M.E. The greenness of China: Household carbon dioxide emissions and urban development. J. Econ. Geogr. 2010, 11, 761-792. [CrossRef]

44. Tarancón Morán, M.Á.; del Río González, P. A combined input-output and sensitivity analysis approach to analyse sector linkages and $\mathrm{CO}_{2}$ emissions. Energy Econ. 2007, 29, 578-597. [CrossRef]

45. Zha, D.; Zhou, D.; Zhou, P. Driving forces of residential $\mathrm{CO}_{2}$ emissions in urban and rural China: An index decomposition analysis. Energy Policy 2010, 38, 3377-3383.

46. Yin, X.; Hao, Y.; Yang, Z.; Zhang, L.; Su, M.; Cheng, Y. Changing carbon footprint of urban household consumption in Beijing: Insight from a nested input-output analysis. J. Clean. Prod. 2020, 258, 120698. [CrossRef]

47. Wang, P.; Wu, W.; Zhu, B.; Wei, Y. Examining the impact factors of energy-related $\mathrm{CO}_{2}$ emissions using the STIRPAT model in Guangdong Province, China. Appl. Energy 2013, 106, 65-71. [CrossRef]

48. Zhu, Q.; Wei, T. Household Energy Use and Carbon Emissions in China: A decomposition analysis. Environ. Policy Gov. 2015, 25, 316-329. [CrossRef]

49. Miao, L.; Gu, H.; Zhang, X.; Zhen, W.; Wang, M. Factors causing regional differences in China's residential $\mathrm{CO}_{2}$ emissionsEvidence from provincial data. J. Clean. Prod. 2019, 224, 852-863. [CrossRef]

50. Wang, Y.; Yang, G.; Dong, Y.; Cheng, Y.; Shang, P. The Scale, Structure and Influencing Factors of Total Carbon Emissions from Households in 30 Provinces of China-Based on the Extended STIRPAT Model. Energies 2018, 11, 1125. [CrossRef]

51. Ang, B.W.; Liu, N. Handling zero values in the logarithmic mean Divisia index decomposition approach. Energy Policy 2007, 35, 238-246. [CrossRef]

52. Ang, B.W. The LMDI approach to decomposition analysis: A practical guide. Energy Policy 2005, 33, 867-871. [CrossRef]

53. National Bureau of Statistic of China. China Energy Statistical Yearbook; China Statistics Press: Beijing, China, 2001-2018. (In Chinese)

54. Guidelines for the Preparation of Provincial Greenhouse Gas Inventories (for Trial Implementation). Available online: https: //wenku.baidu.com/view /7ae95325f111f18583d05a67.html (accessed on 10 October 2020).

55. Jia, J.; Gong, Z.; Xie, D.; Chen, J.; Chen, C. Analysis of drivers and policy implications of carbon dioxide emissions of industrial energy consumption in an underdeveloped city: The case of Nanchang, China. J. Clean. Prod. 2018, 183, 843-857. [CrossRef]

56. Statistic Bureau of Jiangxi. Jiangxi Statistical Yearbook; China Statistics Press: Beijing, China, 2001-2018. (In Chinese)

57. Statistic Bureau of Henan. Henan Statistical Yearbook; China Statistics Press: Beijing, China, 2001-2018. (In Chinese)

58. Statistic Bureau of Hunan. Hunan Statistical Yearbook; China Statistics Press: Beijing, China, 2001-2018. (In Chinese)

59. Statistic Bureau of Hubei. Hubei Statistical Yearbook; China Statistics Press: Beijing, China, 2001-2018. (In Chinese)

60. Statistic Bureau of Shanxi. Shanxi Statistical Yearbook; China Statistics Press: Beijing, China, 2001-2018. (In Chinese)

61. Statistic Bureau of Anhui. Anhui Statistical Yearbook; China Statistics Press: Beijing, China, 2001-2018. (In Chinese)

62. Zhang, M.; Song, Y.; Li, P.; Li, H. Study on affecting factors of residential energy consumption in urban and rural Jiangsu. Renew. Sustain Energy Rev. 2016, 53, 330-337. [CrossRef]

63. Zhao, X.; Li, N.; Ma, C. Residential energy consumption in urban China: A decomposition analysis. Energy Policy 2012, 41, 644-653. [CrossRef] 